\title{
Wine and Health: A Review
}

\author{
Jacquelyn M. Guilford ${ }^{1}$ and John M. Pezzuto ${ }^{1 *}$
}

\begin{abstract}
As indicated by epidemiological studies, regular and moderate wine consumption, particularly red wine, has been associated with health benefits. Clinical studies and work performed with animal models indicate that wine may protect against cardiovascular disease, atherosclerosis, hypertension, certain types of cancer, type 2 diabetes, neurological disorders, and metabolic syndrome. The mechanism of action has been attributed to antioxidant, lipid regulating, and anti-inflammatory effects. A variety of wine constituents have been studied in various disease models. Both the alcoholic and polyphenolic components of wine are believed to contribute to these beneficial effects. As wine is a complex mixture, it is likely that a multitude of chemical constituents, as well as their metabolites, work synergistically to impact human health. In sum, although wine drinking may be contraindicated in certain individuals, in healthy people, regular consumption of moderate amounts of wine may protect against certain chronic health conditions.
\end{abstract}

Key words: antioxidant, cancer, cardiovascular disease, diabetes, polyphenols, resveratrol, wine

Abbreviations: CRP, C-reactive protein; eNOS, endothelial NO synthase; GER, gastroesophageal reflux; GSE, grape seed extract; GSPE, grape seed proanthocyanidin extract; HDL, high-density lipoprotein; LDL, low-density lipoprotein; NO, nitric oxide; PAI-1, plasminogen activator inhibitor-1; t-PA, tissue plasminogen activator; u-PA, urokinase plasminogen activator; VEGF, vascular endothelial growth factor; VLDL, very low-density lipoprotein

It has been estimated that the medicinal use of wine dates back to $2200 \mathrm{BC}$, making it the oldest known medicine (Robinson 2006). Historically, wine has been used as an antiseptic, a painkiller, and to treat dermatological conditions and digestive disorders (Feher et al. 2005, Robinson 2006). In the early 1990s, media coverage of the French Paradox popularized the health benefits of red wine in the United States and spurred research efforts to examine and explain new connections between wine and health.

The French Paradox is based on epidemiological studies that report a comparatively lower incidence of coronary heart disease in France despite high levels of saturated fat in the traditional French diet. A moderate daily consumption of red wine has been proposed to contribute to this effect (Renaud and Gueguen 1998). Additional epidemiological studies from diverse populations have revealed that individuals who habitually consume moderate amounts of wine experience a 20 to $30 \%$ reduction in all-cause mortality, particularly cardiovascular mortality, when compared with individuals who abstain or who drink alcohol to excess (German and Walzem 2000, Ruf 2003). Critics of these studies argue that the average moderate wine drinker is more likely to exercise, to be health conscious, and to be of a higher educational and socioeconomic class (Lindberg and Amsterdam 2008). Despite

${ }^{1}$ University of Hawaii at Hilo, College of Pharmacy, 34 Rainbow Drive, Hilo, HI 96720

*Corresponding author (email: pezzuto@hawaii.edu; fax: 808 933-2981)

Acknowledgments: Work in the laboratory of the authors is supported by program project P01 CA48112 awarded by the National Cancer Institute.

This review was presented in part by J.M. Pezzuto at the 2010 International Cool Climate Symposium, 20-22 June 2010, Seattle, WA.

Manuscript submitted Feb 2011, revised June 2011, accepted June 2011

Copyright (C) 2011 by the American Society for Enology and Viticulture. All rights reserved.

doi: 10.5344/ajev.2011.11013 these potential confounding factors, there is a growing body of evidence from studies performed in animals and humans that support a connection between regular moderate wine drinking and improved health.

There is also a large body of evidence that supports the health benefits derived from grapes, grape juice, and grape seed extract (GSE). These products have been used to treat a variety of conditions, including cancer, cardiovascular disease, ischemic stroke, neurodegenerative disorders, aging, hypertension, hyperlipedemia, and dental caries (Perez-Jimenez and Saura-Calixto 2008, Iriti and Faoro 2009, Kaur et al. 2009, Nassiri-Asl and Hosseinzadeh 2009, Wu 2009, Yadav et al. 2009). Although the chemical constituents of grapes and wine vary to some degree, similar therapeutic effects have been attributed to wine. Some investigators believe these benefits may actually be enhanced in wine, perhaps due to additive effects with the alcohol component of wine and/or to an increased bioavailability of wine polyphenols as a result of the fermentation process.

The mechanisms responsible for the healthful effects of wine are extremely complex. Both the alcohol and the polyphenol components have been extensively studied and there is controversy over which component is more important (Rimm et al. 1996, Hansen et al. 2005). It has been well documented that a moderate intake of alcoholic beverages produces positive effects on antioxidants, lipids, and platelets (reviewed in Lindberg and Amsterdam 2008). Other studies provide evidence that wine demonstrates beneficial properties that are independent from the presence of alcohol, which has been attributed to the polyphenol content of wine (reviewed in Ruf 2003, Halpern 2008). Red wine has been shown to confer a greater degree of health benefits than white wine. Wine polyphenols, which mainly originate from the skins and seeds of grapes, are present in a greater variety and concentration in red wine than in white wine. 
Red wine polyphenols are a complex mixture of flavonoids (such as anthocyanins and flavan-3-ols) and nonflavonoids (such as resveratrol, cinnamates, and gallic acid). Flavan-3-ols are the most abundant, with polymeric procyanidins (condensed tannins) composing up to $50 \%$ of the total phenolic constituents (Waterhouse 2002). Examples of compounds found in grapes with known health benefits include melatonin, catechins, ellagic acid, lutein, quercetin, and resveratrol (Leifert and Abeywardena 2008, Pezzuto 2008). These compounds act as potent antioxidants, reduce harmful low-density lipoprotein (LDL) cholesterol oxidation, modulate cell signaling pathways, and reduce platelet aggregation. Chemical interactions between these and potentially hundreds, if not thousands, of other wine constituents, interact to produce a pleiotropic array of therapeutic effects.

Resveratrol has been extensively studied as a critical constituent that contributes to the health benefits of red wine. Resveratrol, which alters lipid metabolism, inhibits LDL oxidation, and inhibits platelet aggregation, has exhibited both cardioprotective and chemopreventive effects in animal studies (Guerrero et al. 2009). It also inhibits the growth of some tumor types and exhibits anti-inflammatory, antibacterial, antifungal, antiviral, neuroprotective, antiproliferative, and antiangiogenic activities (Nassiri-Asl and Hosseinzadeh 2009).

A class of red wine polyphenols that has been identified as especially protective is the procyanidins. Red wines from southwestern France and Sardinia, Italy, have between two and four times as much procyanidins as other red wines. These regional wines have been suggested to contribute to the longer lifespan noted in these populations (Corder et al. 2006). However, it should be noted that procyanidins have a low bioavailability.

\section{Antioxidant Effects}

The antioxidant effects associated with moderate wine drinking may be one of the factors responsible for the French Paradox. A high fat diet is known to cause high levels of oxidative damage to plasma lipoproteins, which is counteracted by antioxidants present in wine. Oxidative stress is also associated with chronic diseases, including atherosclerosis, heart failure, cancer, and neurological degeneration, and is believed to accelerate the aging process. Red wine has been shown to protect against each of these conditions by increasing plasma antioxidant capacity, suppressing reactive oxygen species generation, increasing serum oxygen radical absorbance capacity, and decreasing oxidative DNA damage. The oxidation of LDL cholesterol is strongly associated with cardiovascular disease. It has been demonstrated that wine flavonoids protect against LDL oxidation (Aviram and Fuhrman 2002, Ursini and Sevanian 2002). Wine procyanidins have been shown to be especially active in preventing lipid oxidation of foods while in the digestive tract, indicating that red wine consumption with a meal affords the most protection (Ursini and Sevanian 2002).

The balance between alcohol and polyphenols in a wine may be critical in determining its antioxidant potential (van
Golde et al. 1999). It is known that alcohol has pro-oxidant effects. Studies performed with dealcoholized wine, grapes, and GSE have shown strong antioxidant effects, indicating that the polyphenol content contributes critically to the antioxidant abilities of wine (Young et al. 2000, Abu-Amsha Caccetta et al. 2001, Bagchi et al. 2002, Durak et al. 2002, O'Byrne et al. 2002, Park et al. 2003, 2009, Vigna et al. 2003, Ko et al. 2005, Zern et al. 2005, Castilla et al. 2006). The antioxidant effects of red wine and of its major polyphenols have been demonstrated with in vitro systems, in cell culture, and in human subjects (Soleas et al. 1997, Fernandez-Pachon et al. 2006, Modun et al. 2008). Important antioxidant components include caffeic acid, catechin, chlorogenic acid, epicatechin, ferulic acid, myricetin, protocatechuic acid, quercetin, and resveratrol (Chopra et al. 2000, Boveris et al. 2002, Afaq et al. 2003). In five samples of red wines from Spain, total antioxidant activity correlated with polyphenol content (Lopez-Velez et al. 2003). In humans, wine polyphenols taken at physiologically relevant concentrations interacted synergistically to produce antioxidant effects (Pignatelli et al. 2006).

An examination of a selection of studies performed in healthy humans (Table 1) reveals that the quantity and pattern of wine consumption are critical determinants of antioxidant outcomes. For example, when only one dose of wine was given, benefits were only transient (i.e., not observed after $3 \mathrm{hr}$ ). When greater than $200 \mathrm{~mL}$ red wine was given daily for up to three weeks, a positive effect was seen in the majority of studies. In studies of four weeks or more, daily consumption of greater than $200 \mathrm{~mL}$ red or white wine improved antioxidant parameters, although there was an indication that the effects were not as great in the case of low-alcohol content wines.

\section{Lipid Effects}

Regular moderate wine consumption is associated with beneficial changes in lipid homeostasis. Wine increases highdensity lipoprotein (HDL) cholesterol, which is important for ridding the body of excess cholesterol. Wine also decreases LDL cholesterol levels, which are associated with a high fat diet. High LDL cholesterol levels are associated with an increased risk of atherosclerosis, obesity, and type 2 diabetes (Njajou et al. 2009). Wine consumption with a meal is believed to be ideal because it allows cholesterol to be cleared before it is deposited in undesired locations in the body.

In a selection of studies measuring lipid effects of wine in healthy humans (Table 2), a single dose of wine was ineffective at modulating lipid levels. Studies performed for two weeks or more indicate that greater than $200 \mathrm{~mL}$ red wine consumption was beneficial. All of the studies with more than one dose indicated that the alcohol component of wine is critical for the beneficial lipid effects, which is supported by the established concept that alcohol raises HDL levels. However, this contradicts observations that grapes, grape juice, and grape extracts positively modulate cholesterol homeostasis (Preuss et al. 2000, Zern et al. 2005, Castilla et al. 2006, Davalos et al. 2006, Sano et al. 2007, Jimenez et al. 2008). Overall, red wine was more effective than white wine, suggesting that wine polyphenols did play a role. 
Although the data presented in Table 2 do not describe a wine-associated decrease in triglyceride levels, there is some evidence that GSE or red wine consumption $(150 \mathrm{~mL}$ for 3 weeks) may combat obesity by decreasing appetite, especially in females (Vogels et al. 2004, Djurovic et al. 2007). One study found that a diet with $10 \%$ of energy derived from white wine or grape juice for 3 months reduced percent body fat, waist circumference, blood pressure, blood glucose, insulin, triglycerides, and cholesterol, and body weight in obese subjects (Flechtner-Mors et al. 2004).

\section{Immune Function/Inflammation}

Chronic inflammation is a critical component in many human diseases and conditions, including obesity, cardiovascular diseases, neurodegenerative diseases, diabetes, aging, and types of cancer. The ethanol and polyphenol components of wine are capable of modulating immune responses (reviewed in Magrone et al. 2008). Changes in inflammatory biomarkers in human subjects suggest that red wine is capable of protecting against various immune-related disorders by both stimulating the innate and adaptive immune responses as well as reducing inflammation. Examples of these changes include suppression of inflammatory cytokine release (such as nuclear factor-kappaB) and induction of anti-inflammatory cytokine release and other protective molecules (i.e., interleukins $1 \alpha, 6$, 10,12 , and interferon-gamma). Nitric oxide (NO), which protects against infections, has been shown to be released from peripheral blood mononuclear cells in response to red wine polyphenols. Inflammatory biomarkers that are reduced by wine drinking include C-reactive protein (CRP), monocyte, and endothelial adhesion molecules (ICAM-1, vascular CAM1, E-selectin, LFA-1, Mac-1, VLA-4, MCP-1). Wine is also

\begin{tabular}{|c|c|c|}
\hline Dose/effect ${ }^{a}$ & Finding & Reference \\
\hline \multicolumn{3}{|l|}{ One dose } \\
\hline$(-)$ & Red wine did not affect LDL oxidation after $1-4 \mathrm{hr}$ & Caccetta et al. 2000 \\
\hline$(-)$ & Red wine taken with a high fat meal did not influence lipid peroxidation & Blackhurst and Marais 2006 \\
\hline$(-)$ & $300 \mathrm{~mL}$ wine did not prevent oxidation of LDL after $96 \mathrm{hr}$ & Ziegler et al. 2005 \\
\hline$(+)$ & $100 \mathrm{~mL}$ red wine enhanced the antioxidant capacity of plasma after $30 \mathrm{~min}$ & Duthie et al. 1998 \\
\hline$(+)$ & $\begin{array}{l}\text { Red wine significantly increased antioxidant potential values of plasma and erythrocytes } \\
\text { after } 1.5 \mathrm{hr} \text { and declined to basal values at } 4.5 \mathrm{hr}\end{array}$ & Durak et al. 1999 \\
\hline$(+)$ & $\begin{array}{l}400 \mathrm{~mL} \text { red (but not dealcoholized red) wine significantly increased plasma antioxidant } \\
\text { capacity }\end{array}$ & Kiviniemi et al. 2007. \\
\hline$(+)$ & Red wine increased plasma antioxidant capacity after $30 \mathrm{~min}$ to $3 \mathrm{hr}$ & Modun et al. 2008 \\
\hline \multicolumn{3}{|c|}{$\begin{array}{l}\text { Daily consumption, } \\
\text { less than four weeks }\end{array}$} \\
\hline$(-)$ & $200 \mathrm{~mL}$ red or white for 10 days had no effect on antioxidant status & Sharpe et al. 1995 \\
\hline$(-)$ & $375 \mathrm{~mL}$ red or white wine for 2 weeks did not reduce lipid peroxidation (in smokers) & Abu-Amsha Caccetta et al. 2001 \\
\hline$(-)$ & $\begin{array}{l}4 \text { glasses }\left(600 \mathrm{~mL}^{\mathrm{b}} \text { ) red wine for } 3 \text { weeks had no significant effect on overall antioxidant }\right. \\
\text { status (no washout period between wine, beer, spirit, and water conditions) }\end{array}$ & van der Gaag et al. 2000 \\
\hline$(+)$ & $\begin{array}{l}200 \mathrm{~mL} \text { red wine with three meals (meat soaked in red wine) prevented absorption of } \\
\text { malondialdehyde, a cytotoxic lipid peroxidation product }\end{array}$ & Gorelik et al. 2008 \\
\hline$(+)$ & $\begin{array}{l}250 \mathrm{~mL} \text { red wine for } 4 \text { days decreased oxidized LDL levels and increased antioxidant } \\
\text { enzyme activity }\end{array}$ & Covas et al. 2003 \\
\hline$(+)$ & $400 \mathrm{~mL}$ red wine for 2 weeks increased antioxidant status and decreased oxidative stress & Micallef et al. 2007 \\
\hline$(+)$ & $\begin{array}{l}375 \mathrm{~mL} \text { red wine daily for } 2 \text { weeks improved antioxidant status and indices of oxidative } \\
\text { stress }\end{array}$ & Tsang et al. 2005 \\
\hline$(+)$ & $\begin{array}{l}400 \mathrm{~mL} \text { red (but not white) wine for } 2 \text { weeks reduced the susceptibility of human plasma } \\
\text { and LDL to lipid peroxidation }\end{array}$ & Fuhrman et al. 1995 \\
\hline$(+)$ & $\begin{array}{l}375 \mathrm{~mL} \text { red wine for } 2 \text { weeks (or isolated red wine polyphenols dissolved in white wine) } \\
\text { reduced LDL oxidation }\end{array}$ & Nigdikar et al. 1998 \\
\hline$(+)$ & Equivalent to $375 \mathrm{~mL}$ alcohol-free red wine extract for 2 weeks inhibited LDL oxidation & Chopra et al. 2000 \\
\hline$(+)$ & $375 \mathrm{~mL}$ red wine (or grape juice) for 2 weeks inhibited oxidation of LDL & van Golde et al. 1999 \\
\hline \multicolumn{3}{|c|}{$\begin{array}{l}\text { Daily consumption, } \\
\text { four weeks or more }\end{array}$} \\
\hline$(-)$ & $\begin{array}{l}\text { 1 glass red wine (or dealcoholized red wine) }\left(150 \mathrm{~mL}^{\mathrm{b}}\right) \text { for } 6 \text { weeks did not increase } \\
\text { plasma antioxidant capacity }\end{array}$ & Arendt et al. 2005 \\
\hline$(-)$ & $\begin{array}{l}550 \mathrm{~mL} \text { low-alcohol (3.5\%) red or white wine for } 4 \text { weeks did not prevent LDL oxidation } \\
\text { or change the level of antioxidants in the blood }\end{array}$ & de Rijke et al. 1996 \\
\hline$(+)$ & $250 \mathrm{~mL}$ red wine for 2 months reduced oxidative stress (acute coronary syndrome patients) & Guarda et al. 2005 \\
\hline$(+)$ & $\begin{array}{l}240 \mathrm{~mL} \text { red wine for } 3 \text { months increased plasma antioxidant capacity and decreased } \\
\text { oxidative DNA damage }\end{array}$ & Leighton et al. 1999 \\
\hline$(+)$ & $\begin{array}{l}375 \mathrm{~mL} \text { white wine for } 1 \text { month increased the activity of antioxidant enzymes and } \\
\text { decreased the activity of pro-oxidant enzymes }\end{array}$ & Rajdl et al. 2007 \\
\hline
\end{tabular}

aPlus (+) indicates a positive response was observed; minus (-) indicates no effect.

${ }^{b}$ Due to the lack of standardization of wine dosage in clinical trials, calculations were performed to provide dosage equivalents in $\mathrm{mL}$ when necessary. These calculation estimates, provided for comparison purposes only, were based on $1 \mathrm{glass}$ of wine $=150 \mathrm{~mL}=13.7 \mathrm{~g}$ alcohol. 
associated with a reduction in fibrinogen, plasma viscosity, and white blood cell count (Estruch et al. 2004, Imhof et al. 2004). In human and animal studies, grape juice and grape extract also supported immune function and exhibited antiinflammatory effects, supporting a role for wine polyphenols (Zern et al. 2005, Castilla et al. 2006, 2008, Percival 2009).

Analysis of a selection of studies performed in healthy humans (Table 3) shows that positive effects on immune function require greater than two weeks of consumption at levels of at least two glasses of wine $(300 \mathrm{~mL})$ daily for men (less for women). Red wine appears to have greater positive effects than white wine. The importance of the alcohol content is not clear from these studies. However, an epidemiological study performed at multiple European sites found that moderate daily consumption of either wine or beer were both associated with lower levels of systemic inflammatory markers compared to nondrinking and heavy drinking individuals, indicating a role of alcohol (Imhof et al. 2004).

\section{Cardiovascular Effects}

Cardiovascular diseases are the leading cause of death worldwide in both men and women. Moderate wine consump- tion (one to two glasses daily) has been associated with decreased cardiovascular mortality and decreased risk of heart disease in epidemiological studies and meta-analyses (de Gaetano et al. 2003). These benefits have been attributed to increased antioxidant capacities, changes in lipid profiles, and anti-inflammatory effects (reviewed in Cordova et al. 2005, Dohadwala and Vita 2009). Other contributing effects include decreased platelet aggregation, improved endothelial function, and increased fibrinolysis. Regular red wine consumption may especially benefit those at risk for atherosclerosis, hypertension, and hypercholesterolemia (Wang et al. 2002, Coimbra et al. 2005, Jimenez et al. 2008). Human studies have demonstrated that white wine, red wine, and GSE each significantly increased adiponectin levels, indicating a decreased risk of myocardial infarction (Sano et al. 2007, Joosten et al. 2008, Imhof et al. 2009).

Two meta-analyses performed in 2002 identified a doseresponse relation between wine intake and vascular risk resulting in a J-shaped curve, suggesting that moderate drinkers may benefit while abstainers and heavy drinkers are at higher risk. The first analysis, which included 13 studies involving 209,418 people, found that the relative risk of vascular

Table 2 Effect of wine consumption on lipid parameters in healthy humans.

\begin{tabular}{lll}
\hline Dose/effect ${ }^{a}$ & Finding & Reference \\
\hline
\end{tabular}

One dose

(-) $\quad$ Red wine after $6 \mathrm{hr}$ exacerbated the postprandial lipid and insulin response (postmenopausal women)

$(-) \quad$ Wine (with food) raised plasma triglyceride levels without significantly changing cholesterol levels

$(-) \quad$ Red wine (but not vodka) with a high fat meal after 3-9 hr increased certain serum lipids, particularly very low-density lipoprotein (VLDL)

\section{Daily consumption,}

less than four weeks

(-) $\quad 200 \mathrm{~mL}$ red or white wine for 10 days did not affect total cholesterol, triglycerides, or HDL levels

(-) $\quad$ Equivalent of $375 \mathrm{~mL}$ alcohol-free red wine extract for 2 weeks did not change triglyceride, total cholesterol, LDL, or HDL cholesterol levels

(+) $250 \mathrm{~mL}$ red wine for 4 days (outside mealtime) decreased the LDL/HDL cholesterol ratio

(+/-) $\quad 300 \mathrm{~mL}$ (males) or $200 \mathrm{~mL}$ (females) red wine (but not red grape extract) for 4 weeks increased HDL cholesterol; no changes were observed with LDL or total cholesterol levels

(+) $\quad 375 \mathrm{~mL}$ red wine for 2 weeks increased HDL cholesterol levels

(+) $\quad 30 \mathrm{~g}$ alcohol $\left(300 \mathrm{~mL}^{\mathrm{b}}\right)$ red (but not dealcoholized red) wine for 2 weeks slightly increased HDL cholesterol and increased efflux of cellular cholesterol

(+/-) $\quad 400 \mathrm{~mL}$ red wine (but not white wine) for 2 weeks increased plasma HDL and triglyceride concentrations; total cholesterol and LDL levels did not change

\section{Daily consumption,}

four weeks or more
$(+)$
$20 \mathrm{~g}$ ethanol $\left(220 \mathrm{~mL}^{\mathrm{b}}\right)$ red or white wine for 4 weeks increased HDL cholesterol (females)
(+) $\quad 375 \mathrm{~mL}$ white wine for 1 month increased HDL cholesterol and paraoxonase 1
$(+/-) \quad 375 \mathrm{~mL}$ red or white wine (but not grape juice) for 4 weeks raised plasma HDL cholesterol; total cholesterol and triglyceride levels were also increased
(+) $\quad 400 \mathrm{~mL}$ red (but not dealcoholized red) wine for 6 weeks reduced LDL cholesterol and increased HDL cholesterol (mildly hypercholesterolemic postmenopausal women)
$(+)$

Naissides et al. 2004

Van Tol et al. 1995

Blanco-Colio et al. 2000

Sharpe et al. 1995

Chopra et al. 2000

Covas et al. 2003

Hansen et al. 2005

Tsang et al. 2005

Senault et al. 2000

Lavy et al. 1994

Sacanella et al. 2007

Rajdl et al. 2007

Goldberg et al. 1996

Naissides et al. 2006a

Gottrand et al. 1999

aplus (+) indicates a positive response was observed; minus (-) indicates no effect.

${ }^{b}$ Due to the lack of standardization of wine dosage in clinical trials, calculations were performed to provide dosage equivalents in $\mathrm{mL}$ when necessary. These calculation estimates, provided for comparison purposes only, were based on $1 \mathrm{glass}$ of wine $=150 \mathrm{~mL}=13.7 \mathrm{~g}$ alcohol. 
disease associated with one glass of wine $(150 \mathrm{~mL})$ daily was 0.68 (95\% CI: 0.59-0.77) compared with nondrinkers (Di Castelnuovo et al. 2002). The second meta-analysis included 19 studies and also found a negative association of moderate wine consumption with the risk of cardiovascular events, with a significant risk reduction at two drinks $(300 \mathrm{~mL})$ per day (de Gaetano et al. 2002). A meta-analysis performed in 1999 found that consumption of one to four drinks per day was associated with a slightly reduced risk of mortality and coronary heart disease (Cleophas 1999). However, this study did not find an increased benefit of wine over beer or spirits.

There is conflicting evidence as to whether the alcohol or the polyphenol content of red wine is responsible for its cardioprotective effects. Moderate consumption of alcohol elevates HDL cholesterol, lowers fibrinogen plasma levels, and may prevent platelet aggregation. Red wine polyphenols exhibit antioxidant, vasorelaxant, and antithrombotic properties (Opie and Lecour 2007). Red wine polyphenols that have been implicated in protection against myocardial ischemic reperfusion injury in animal models include resveratrol and proanthocyanidins (Das et al. 1999, Rakotovao et al. 2004, Opie and Lecour 2007). There is evidence that white wine may also be cardioprotective due to alcohol and antioxidant (caffeic acid, tyrosol, and hydroxytyrosol) components (Bertelli 2007). Overall, numerous studies support the finding that wine, especially red wine, is cardioprotective.

Coagulation and platelet function. Several studies have concluded the alcohol component of wine is largely responsible for its antiplatelet activities (Pace-Asciak et al. 1996, Pellegrini et al. 1996). Alcohol has anticoagulant properties that limit blood clotting by making platelets less prone to stick together and reducing the levels of fibrin protein that binds them together. However, more recent studies implicate wine polyphenols as the key mediator (reviewed in Ruf 2004). Clinical trials demonstrating that grapes and grape juice decrease platelet aggregation support the polyphenol argument (Folts 1998, Keevil et al. 2000). That is contradicted by findings that $300 \mathrm{~mL}$ of white wine daily for two weeks exhibited a higher antiplatelet activity than red wine with the same alcohol content (Pignatelli et al. 2002). However, the most likely case is that the benefits of alcohol and polyphenols are additive, which is supported by findings that alcohol, red wine, and polyphenolic grape extract each inhibited platelet adhesion in human blood (de Lange et al. 2004).

There is evidence that the effects of wine on blood coagulation may only be transient, indicating that moderate chronic consumption is critical for beneficial outcomes (Lavy et al. 1994, Kikura et al. 2004). This could explain conflicting data regarding the effect of wine on levels of fibrinogen, tissue plasminogen activator (t-PA), plasminogen activator inhibitor-1 (PAI-1), plasma protein C, CRP, von Willebrand factor, antithrombin III, plasminogen, factors VII and VIII, as well as measurements of bleeding time, platelet counts, platelet aggregation, prothrombin time, partial thromboplastin time, activated cephalin time, and thrombin-antithrombin complexes (Lavy et al. 1994, Pellegrini et al. 1996, van Golde et al. 2003, Mezzano 2004, Coimbra et al. 2005, Hansen et al. 2005). There are indications that inconsistencies in diet (i.e., high fat vs. low fat) between studies may also confound the results (Mezzano 2004). Another complication is that the assay techniques (i.e., using fibrinogen vs. collagen to stimulate platelet aggregation) apparently affect the outcome (de Lange et al. 2004, Mezzano 2004). It is not clear if this is relevant for in vivo situations.

Endothelial function. Endothelial dysfunction is an indicator of poor prognosis in most forms of cardiovascular

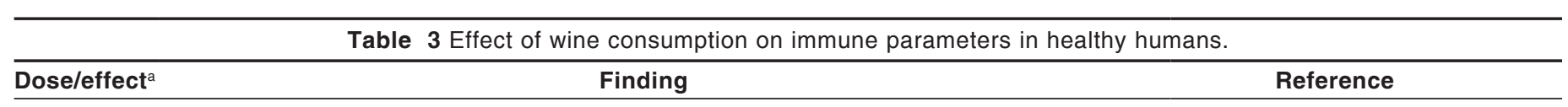

\section{One dose}

$(-)$
(+) Red wine (but not vodka) after 3-9 hr intake prevented nuclear factor-kappaB activation

$500 \mathrm{~mL}$ red wine (or grape juice or dealcoholized red wine) after $24 \mathrm{hr}$ did not affect biomarkers of immune status less than four weeks

$(-)$

$500 \mathrm{~mL}$ red wine (or alcohol, dealcoholized red wine, or grape juice) for 2 weeks did not affect biomarkers of immune status

Daily consumption,

four weeks or more

$(-)$

$(-/+)$

$(+)$

$(+)$

$(+)$
$200 \mathrm{~mL}$ red wine (or dealcoholized red wine) for 6 weeks did not modulate immunological functions of leukocytes

$150 \mathrm{~mL}$ red wine for 3 weeks slightly reduced fibrinogen levels but did not reduce CRP levels

$20 \mathrm{~g}$ ethanol $\left(220 \mathrm{~mL}^{\mathrm{b}}\right)$ red or white wine by females for 4 weeks caused a down-regulation of adhesion molecules and other inflammatory biomarkers; red wine was more effective than white wine

Greater than 14 drinks red wine per week ( $300 \mathrm{~mL}$ daily ${ }^{\mathrm{b}}$ ) (but not consumption of other alcoholic beverages) was associated with a decreased risk of common cold

$30 \mathrm{~g}$ alcohol $\left(330 \mathrm{~mL}^{\mathrm{b}}\right)$ red wine or gin for 1 month showed anti-inflammatory effects
Watzl et al. 2002

Blanco-Colio et al. 2000

Watzl et al. 2004

Ellinger et al. 2008

Retterstol et al. 2005

Sacanella et al. 2007

Takkouche et al. 2002

Estruch et al. 2004

aplus (+) indicates a positive response was observed; minus (-) indicates no effect.

${ }^{b}$ Due to the lack of standardization of wine dosage in clinical trials, calculations were performed to provide dosage equivalents in $\mathrm{mL}$ when necessary. These calculation estimates, provided for comparison purposes only, were based on $1 \mathrm{glass}$ of wine $=150 \mathrm{~mL}=13.7 \mathrm{~g}$ alcohol. 
disease. Endothelial cells play a major role in regulating the balance between the synthesis and interaction of proteins that promote clot formation and fibrinolytic proteins that facilitate fibrinolysis (clot lysis). The endothelium regulates vascular tone by releasing NO (vasorelaxant) or endothelins (vasoconstrictors). Constricted blood vessels raise blood pressure and are more prone to clot formation. In animal models, wine polyphenols caused endothelium-dependent vasorelaxation associated with NO stimulating activity (Caimi et al. 2003b). Red wine polyphenols that promote endothelium-dependent NO production include catechin, quercetin, procyanidins, and resveratrol (Gresele et al. 2008). Wine polyphenols are believed to also have a longer-term effect by increasing endothelial NO synthase (eNOS) expression (Dell'Agli et al. 2004). Wine polyphenol content was found to correlate with inhibition of synthesis of endothelin-1 (Corder et al. 2006). A short-term supplementation of red wine caused a significant increase in circulating endothelial progenitor cells in mice (Balestrieri et al. 2008).

A favorable action of red wine, dealcoholized wine extract, or purple grape juice on endothelial function has been observed. However, ethanol alone has been shown to cause vasodilatation, making the discrimination between ethanol and polyphenol effects controversial. Short-term ingestion of red wine or purple grape juice improved endothelial function in patients with coronary artery disease (Stein et al. 1999, Whelan et al. 2004). Such benefits were not observed when more than five glasses of wine were consumed at once (binge drinking), a level at which alcohol may become toxic (Hijmering et al. 2007). Another study found dealcoholized red wine to be more effective than regular red wine (Agewall et al. 2000), but there are data that contradict these results (Boban et al. 2006, Naissides et al. 2006b).

Red wine consumption has been demonstrated to enhance endothelium-independent vasodilatation in hypercholesterolemic patients (Coimbra et al. 2005). Red wine counteracted the reduction of endothelial function caused by a high fat diet when moderate amounts were consumed over the long term (Cuevas et al. 2000), but not the short term (Djousse et al. 1999). Consumption of red wine and green olive oil with a meal was found to improve the postprandial endothelial function in a synergistic manner, which may involve an elevated plasma antioxidant capacity (Karatzi et al. 2008). Another study did not find a benefit of drinking one glass of red wine with a meal (Napoli et al. 2004), indicating that long-term consumption may be necessary for optimal results. Overall, regular, moderate red wine consumption has been demonstrated to improve endothelial function.

Fibrinolysis. Both ethanol and polyphenols present in wine have been shown to modulate fibrinolysis (Booyse et al. 2007). Either $30 \mathrm{~g}$ alcohol or the equivalent amount of red wine $(\sim 300 \mathrm{~mL})$ daily for four weeks reduced fibrinogen levels in healthy humans (Pellegrini et al. 1996). Similar effects were found when $300 \mathrm{~mL}$ (males) or $200 \mathrm{~mL}$ (females) of red wine (but not red grape extract) were consumed daily for four weeks (Hansen et al. 2005). Endothelial cell-mediated upregulation of t-PA and urokinase plasminogen activator
(u-PA) activity and downregulation of PAI-1 (the major inhibitor/regulator of fibrinolysis) may be involved (Pasten and Grenett 2006). There are indications that long-term moderate red wine consumption is required for positive effects and that exercise may enhance these benefits (Johansen et al. 1999).

Atherosclerosis. Studies performed with in vitro systems, in animals, and in human subjects have shown that red wine polyphenols interfere with the initiation, progression, and rupture of atherosclerotic plaques by exhibiting antioxidant, antiplatelet, and antithrombotic activities (reviewed in Aviram and Fuhrman 2002, Szmitko and Verma 2005, Lagrue-Lak-Hal and Andriantsitohaina 2006). Red wine polyphenols lower blood pressure, reduce inflammation, improve endothelial function, decrease the expression of adhesion molecules, and inhibit smooth muscle cell proliferation and migration (Dell'Agli et al. 2004). These processes all interfere with atherosclerotic plaque development, vascular thrombosis, and occlusion.

Red wines have exhibited positive effects on biomarkers of atherosclerosis in healthy humans, including a decrease in the LDL/HDL ratio, fibrinogen levels, lipoprotein (a), clotting factors, CRP, and oxidized LDL levels (Sharpe et al. 1995, Avellone et al. 2006). Also, increases in HDL cholesterol, TGFbeta, t-PA, PAI-1, membrane fluidity, and total plasma antioxidant capacity were reported. Human studies have demonstrated that short-term interventions with moderate amounts of ethanol, dealcoholized red wine, or low polyphenol sparkling wine reduced the risk of atherosclerosis, as measured by biomarkers (Vazquez-Agell et al. 2007, Imhof et al. 2008). These data indicate that the alcohol and polyphenol wine components are both important and have additive effects There is a report that one dose of $400 \mathrm{~mL}$ of red wine, but not dealcoholized red wine, increased coronary flow reserve in humans (Kiviniemi et al. 2007). However, another study cautioned that one month of white wine consumption caused a significant increase in pro-atherogenic homocysteine levels (Rajdl et al. 2007).

Hypertension. Red wine polyphenols have vasorelaxing effects, which are associated with lower blood pressure (Carollo et al. 2007). Red wine, dealcoholized red wine, and grape juice consumption have lowered blood pressure in patients with coronary artery disease or hypertension (Foppa et al. 2002, Park et al. 2004, Karatzi et al. 2005, Jimenez et al. 2008). Benefits appear to be greater when red wine (and to a lesser extent white wine) is consumed during a meal ( $\mathrm{Pa}-$ pamichael et al. 2008). These data suggest that polyphenols, rather than alcohol, are responsible for the health benefits. The presence of garlic, onions, fish, and olive oil in the Mediterranean diet (associated with a decreased risk of hypertension) provide additional hypotensive compounds that likely act in a synergistic manner with those present in wine (de Lorgeril et al. 2008).

The effects of wine drinking in normotensive individuals are conflicting. Studies with humans subjects have found that moderate red wine consumption over the course of a month either did not change or increased both systolic blood 
pressure and heart rate, which was attributed to the alcohol content (Hansen et al. 2005, Zilkens et al. 2005). Another study found that one drink of red wine had vasorelaxing effects, whereas two drinks had the opposite effect (Spaak et al. 2008). Moderate to heavy alcohol consumption has been associated with increased blood pressure.

\section{Cancer}

Despite the fact that alcohol is a known carcinogen, there is evidence that moderate wine consumption may decrease the risk of several cancers, including colon, basal cell carcinoma, ovarian, and prostate (Bianchini and Vainio 2003). Consumption of approximately one glass of wine daily was associated with a decreased risk of developing Barrett's esophagus, a precursor to esophageal adenocarcinoma, when compared to heavy drinkers or nondrinkers (Kubo et al. 2009). A metaanalysis found that modest wine consumption had an inverse association for developing lung cancer, for both average wine consumption of less than one drink per day (RR, $0.77 ; 95 \%$ CI, 0.59-1.00) and one drink or greater per day (RR, 0.78; 95\% CI, 0.60-1.02) (Chao 2007). A study of female nonHodgkin's lymphoma patients found a significantly better five-year overall survival (75\% vs. 69\%) and five-year disease free survival (70\% vs. 67\%) in occasional wine drinkers versus abstainers (Han et al. 2010). Compared to nondrinkers, women who drank wine for at least 25 years prior were $33 \%$ less likely to die and $26 \%$ less likely to experience a relapse or develop a secondary cancer over the five-year period following diagnosis. No advantage of beer or alcohol consumption was found. However, heavy drinking and alcoholism, along with smoking, are leading causes of upper aero-digestive cancers. There is a large body of evidence from epidemiological as well as animal studies that chronic alcohol intake is associated with increased breast cancer risk (Dumitrescu and Shields 2005). There is limited evidence of an increased risk of cancer of the oral cavity and pharynx in populations with frequent wine consumption (Altieri et al. 2004).

In vitro and animal studies indicate that red wine polyphenols inhibit angiogenesis by reducing the proliferation and migration of endothelial and vascular smooth muscle cells and the expression of proangiogenic factors (vascular endothelial growth factor [VEGF] and matrix metalloproteinase-2) (Oak et al. 2005). Evidence that wine polyphenols contribute to the chemopreventive effects of wine come from studies performed with grape seed proanthocyanidin extract (GSPE). GSPE exhibited toxicity toward human breast, lung, and gastric adenocarcinoma cells, but not normal cells (Bagchi et al. 2002, Katiyar 2008). It protected against tobacco toxicity in oral cells, chemotherapy toxicity in liver cells, and ultraviolet toxicity in skin cells. Modulation of oxidative stress, growth factors, and inflammatory molecules were involved (Katiyar 2008).

A high percentage of the literature on the cancer-preventing effects of wine is focused on one compound in particular: resveratrol. Our laboratory was the first to demonstrate the cancer chemopreventive activity of this compound (Jang et al. 1997). Since then, an exhaustive amount of research has been performed on health benefits associated with resveratrol. Although it is only possible to briefly discuss the topic here, many comprehensive reviews have been written on the subject (Bianchini and Vainio 2003, Aggarwal et al. 2004, Aggarwal and Shishodia 2006, Pezzuto 2008, Guerrero et al. 2009, Pezzuto et al. 2009).

Resveratrol suppresses proliferation of a wide variety of tumor cells, including lymphoid, myeloid, breast, prostate, stomach, colon, pancreas, thyroid, skin, head and neck, ovarian, and cervical. Resveratrol has been effective at preventing the formation of skin, oral, colorectal, esophageal, hepatoma, neuroblastoma, glioma, laryngeal, and gastric tumors in animal models. There is conflicting data in animal models regarding inhibition of lung, intestinal, and breast tumorigenesis. Resveratrol has received a great deal of attention because it blocks the multistep process of carcinogenesis at various stages: carcinogen activation, tumor initiation, tumor promotion, and tumor progression (Jang et al. 1997). It has been demonstrated to inhibit carcinogenesis by acting as an antioxidant, anti-inflammatory agent, antimutagen, antimetastatic agent, antiangiogenic agent, antidifferentiation agent, antiproliferative agent, and pro-apoptotic agent. It modulates signal transduction, the immune response, transcription factors, growth factors, cytokines, caspases, interleukins, prostaglandin synthesis, and cell cycle-regulating proteins.

\section{Type 2 Diabetes}

Type 2 diabetes is characterized by decreased disposal of glucose in peripheral tissues, insulin resistance, overproduction of glucose by the liver, and defects in pancreatic betacells. Markers of vascular risk associated with type 2 diabetes include endothelial dysfunction, oxidative stress (especially after meals), inflammation, and insulin resistance. There is evidence that moderate and regular red wine consumption may prevent the onset of type 2 diabetes as well as associated complications (reviewed in Caimi et al. 2003a).

The antioxidant properties of red wine polyphenols may be responsible for the positive responses. The importance of polyphenols is supported by evidence that grapes and GSE provide therapeutic effects in type 2 diabetic patients (Zunino 2009). Resveratrol, quercetin, catechins, and anthocyanins have been shown to inhibit hyperglycemia, improve beta-cell function, and protect against beta-cell loss. In obese Type 2 diabetic subjects, GSE significantly improved inflammation and glycemic status and decreased oxidative stress and total cholesterol levels (Kar et al. 2009). Analyses of epidemiological studies concluded that moderate regular alcohol consumption is associated with an $\sim 30 \%$ reduced risk of type 2 diabetes (Howard et al. 2004, Koppes et al. 2005), indicating that the benefits afforded by the alcohol and polyphenol contents of red wine are probably additive. In postmenopausal women, $250 \mathrm{~mL}$ white wine consumption daily for six weeks improved insulin sensitivity compared to white grape juice (Joosten et al. 2008).

Among patients with type 2 diabetes who had previously abstained from alcohol, initiation of $150 \mathrm{~mL}$ wine 
consumption daily for three months significantly reduced fasting plasma glucose, but not postprandial glucose (Shai et al. 2007). In a study of type 2 diabetes patients that had a previous myocardial infarction, moderate red wine consumption during meals for one year significantly reduced oxidative stress and pro-inflammatory cytokines (CRP, tumor necrosis factor-alpha, IL-6 and IL-18) and improved cardiac function (Marfella et al. 2006). Another study in type 2 diabetics found that $150 \mathrm{~mL}$ muscadine grape wine (especially high in polyphenols) or the dealcoholized version with meals for 28 days lowered levels of blood glucose, insulin, and glycated hemoglobin, and improved antioxidant status and membrane fluidity compared with treatment with muscadine grape juice (Banini et al. 2006). Decreases in sodium, chloride, alanine aminotransferase, and aspartate aminotransferase values indicated a protection against hypertension and liver dysfunction. Daily red wine consumption $(118 \mathrm{~mL})$ for 6 months was renoprotective in type 2 diabetes mellitus patients with nephropathy; benefits were not observed with white wine (Nakamura et al. 2009). However, $190 \mathrm{~mL}$ red wine for 10 weeks in overweight women did not alter diabetes-associated risk factors, including insulin sensitivity, body weight and composition, blood lipids, and blood pressure (Cordain et al. 2000).

\section{Metabolic Syndrome}

Metabolic syndrome is defined by the presence of metabolic risk factors associated with high risk of developing type 2 diabetes and cardiovascular disease. These risk factors include abdominal obesity, high plasma triacylglycerols, low plasma HDL, high blood pressure and high fasting plasma glucose. Several reviews have presented evidence that moderate wine consumption may prevent metabolic syndrome and its related medical complications (Leighton et al. 2006, Liu et al. 2008). A mechanism that may be important is the ability of red wine components to enhance the function of endothelial NO synthase (eNOS), which may not function properly in metabolic syndrome patients (Leighton et al. 2006).

\section{Other Conditions}

There are preliminary data that wine provides health benefits in other areas. For example, red and white wine exhibited antibacterial activity against oral streptococci (Daglia et al. 2007). Moderate wine drinkers were identified to be at a lower risk of developing age-related macular degeneration than nondrinkers (Obisesan et al. 1998). There is evidence that grape procyanidins protect against radiation injury in radiation-contacted humans (Liu and Zhong 2008). Moderate wine consumption has been shown to benefit patients with renal disease by preventing oxidative stress and endothelial dysfunction (Rodrigo and Rivera 2002, Caimi et al. 2004, Presti et al. 2007). Drinking less than four glasses daily was associated with a retention in bone density and reduced risk of developing osteoporosis in elderly women, although detrimental effects on bone mass were observed with higher intakes (Ganry et al. 2000). A retrospective study in healthy centenarians found that moderate wine drinkers $(\leq 500 \mathrm{~mL}$ daily) have lower markers of liver damage compared to those who abstained (Pinzani et al. 2005).

\section{Neurologic Effects}

Epidemiological and animal studies have demonstrated that moderate red wine intake may reduce the risk of developing neurological disorders, such as dementia, stroke, and Alzheimer's disease (reviewed in Letenneur 2004, Pinder and Sandler 2004). Epidemiological studies in women have shown that moderate levels of alcohol intake (approximately one drink per day) may be associated with better cognition and reduced risk of significant cognitive decline, compared to those who abstained (Espeland et al. 2005, Stampfer et al. 2005). Similar results were reported in elderly populations (Ganguli et al. 2005, Peters et al. 2008). There are conflicting data as to whether wine polyphenols provide additional protection beyond that of alcohol (Mehlig et al. 2008), although neuroprotective effects have also been observed with grape juice supplementation in human studies (Joseph et al. 2009). It is likely that the antioxidants present in wine prevent oxidative damage in the brain that is associated with the process of aging. The discovery that some wines contain hydroxytyrosol, a dopamine metabolite and potent antioxidant, suggest that wine constituents may modulate dopamine signaling in the brain (de la Torre et al. 2006). Resveratrol has also been shown to provide neuroprotection by reducing oxidative stress in neuronal cells and regulating signaling pathways involved in memory and learning processes (Tredici et al. 1999).

Red wine is commonly alleged to initiate migraine attacks in susceptible individuals (Littlewood et al. 1988, Sandler et al. 1995). This adverse effect may be caused by a modulation of serotonin levels induced by wine consumption or by specific wine constituents, such as histamine or phenylethylamine (Jarisch and Wantke 1996).

\section{Pulmonary Effects}

There are epidemiologic, clinical, and experimental data supporting positive effects of light-to-moderate wine consumption on lung function, chronic obstructive pulmonary disease progression, and the risk of developing lung cancer, acute respiratory distress syndrome, and high altitude pulmonary edema (Schafer and Bauersachs 2002, Kamholz 2006). Proposed mechanisms for pulmonary protection include suppression of endothelin-1 expression, inhibition of inflammatory cytokine release, and antioxidative properties (Culpitt et al. 2003).

Wine-induced asthmatic symptoms are well documented and have been attributed to natural sulfite levels in all wines as well as sulfur dioxide, which may be used as a wine preservative (Dahl et al. 1986). There is evidence that the cause and incidence of wine-induced asthma may vary between individuals, involving several mechanisms that are codependent, and that sulfites are usually not responsible (Vally et al. 1999, 2007). Histamine in wine may induce coughing and wheezing with a decrease in lung function in patients suffering from histamine intolerance (Wantke et al. 1996). Adverse reactions 
to wine (facial flushing, asthma, and oral allergic swelling and burning) in some cases has been determined to have been caused by a sensitivity to the venom of Hymenoptera insects (wasps, bees, ants), which may contaminate wines during vinification (Armentia 2008). A recent study in asthmatic patients with wine sensitivity reported mast cell activation as a possible mechanism for wine-induced asthma, which did not correlate with wine sulfite levels (Misso et al. 2009).

\section{Gastrointestinal Effects}

A recent survey of 9,733 older adults found that moderate alcohol consumption is associated with a lower infection rate of Helicobacter pylori, with a stronger association in wine than beer drinkers (Gao et al. 2010). Wine constituents have exhibited antibiotic activity against $H$. pylori isolates and protected against associated gastric damage in mice (Daroch et al. 2001, Mahady et al. 2003, Ruggiero et al. 2007, Martini et al. 2009).

White wine has been demonstrated to induce gastroesophageal reflux (GER) in healthy people and GER patients (Vandenbroucke 1991, Grande et al. 1997, Pehl et al. 2000, 2006, Levanon et al. 2002), which may be due to an inhibition of postprandial gastric contractions and/or disturbed esophageal clearance due to an increase in simultaneous contractions and failed peristalsis. Repeated reflux events have been noted to occur. Individuals at risk for acid reflux are advised to limit wine ingestion to $\leq 300 \mathrm{~mL}$ daily.

\section{Toxic Effects}

Although the positive health effects of wine are many, the evidence is clear that these benefits are the highest for those who drink red wine in moderation (two drinks per day for men and one drink per day for women) over extended periods of time. Three or more drinks per day may increase the risk of neurodegeneration, depressive disorders, obesity, weakening of bones, hypertriglyceridemia, heart disease, hypertension, stroke, breast cancer, suicide, and injuries (Saremi and Arora 2008). Wine consumption in any amount is contraindicated for pregnant women, children, patients with liver disease, and in combination with certain medications (Feher et al. 2005). Regular wine consumption should be used with caution in individuals predisposed to alcoholism, organic diseases, cirrhosis of the liver, migraine headaches, and allergies.

Red wine has been shown to decrease the bioavailability of cyclosporine, an immunosuppressant (Tsunoda et al. 2001). In some people, red wine prematurely increased the concentration of extended-release felodipine, a calcium channel blocker (Bailey et al. 2003). A high dosage of resveratrol was found to decrease the bioavailability of nifedipine (an antihypertensive drug) or lovastatin (an antilipemic drug) and to increase the bioavailability of niacin (an antilipemic drug) (Puja et al. 2007). Based on the vasodilating properties of wine, it could theoretically interact with antihypertensive agents. Hypertensive subjects taking vitamin $\mathrm{C}$ concomitantly with grape seed polyphenols experienced an increased systolic blood pressure (Ward et al. 2005). Although it would be expected that the antiplatelet effects of wine would cause an interaction with the anticoagulant warfarin, that has not been the case in human studies (Karlson et al. 1986, Greenblatt et al. 2006). In one study, drinking two glasses of red or white wine in the evening did not significantly increase the risk of suppression of coagulation function the next day (Mezzano 2004).

There are many reports of contaminants in wines that pose potential health risks, including pesticide and fungicide residues, acetic acid, bacteria, lead, fungi, and mycotoxins such as ochratoxin A (Brereton et al. 1997, Cabras and Angioni 2000, Battilani et al. 2006, Chulze et al. 2006, Flamini and Panighel 2006, Hocking et al. 2007, Mateo et al. 2007, Bartowsky and Henschke 2008, Cesnik et al. 2008). Different countries have different regulations for acceptable levels of these contaminants. Arginine metabolism in wine malolactic bacteria may increase the concentration of the carcinogen ethyl carbamate in wine ( $\mathrm{Li}$ et al. 2006). Long-term consumption of red wine may provide potentially toxic levels of chromium, lead, nickel, and vanadium; whether this poses a health risk is under investigation (Hague et al. 2008).

\section{Conclusions}

There is ample evidence supporting the health benefits associated with regular and moderate consumption of wine, particularly polyphenol-rich red wine. The practice has been associated with a decreased risk of cardiovascular conditions, type 2 diabetes, and many types of cancer. The alcohol component increases HDL cholesterol levels, inhibits platelet aggregation, and reduces systemic inflammation. Polyphenols present in wine independently provide antioxidant protection, decrease platelet aggregation, and increase endothelial function. Wine polyphenols also act through a variety of mechanisms to prevent and attenuate inflammatory responses, thereby serving as possible cardioprotective, neuroprotective, and chemopreventive agents.

Wines differ in alcohol and phytochemical content and composition. The question "which wine is the healthiest?" naturally presents itself. It appears that a very tannic, procyanidin rich wine would provide the most benefit. Overall, there appear to be more health benefits associated with red than white wine. However, not all red wines have the same polyphenol content, which could be the most important factor. There is evidence certain polyphenols, such as resveratrol, provide an abundance of health benefits. Yet, resveratrol itself actually has a low bioavailability, indicating that it is the metabolites of resveratrol that are the real key players (Liu and Zhong 2008). Similar results were found for anthocyanins, flavonols, and catechin (Donovan et al. 1999, Bub et al. 2001, de Vries et al. 2001, Frank et al. 2003). Not only does this mean that the actual resveratrol content of wine may not be as important as originally thought, but it also suggests that yet unidentified compounds may be even more important. Of course, these compounds are present in a complex mixture and almost certainly antagonize and synergize in vivo. The complexity increases when considering each person may metabolize wine differently. Even if it were possible to determine that one particular wine type was the "healthiest," 
each vintage is impacted by soil type, geographical region, climate, insecticides, and seasonal variations. Therefore, essentially no two bottles of wine have the exact same chemical composition. The storage procedures and duration of wine aging after it is purchased may also alter its chemical profile.

It must be emphasized that the benefits associated with red wine are dependent upon regular and moderate consumption (Walzem 2008). Although general recommendations are one drink $(150 \mathrm{~mL})$ daily for women and two drinks $(300 \mathrm{~mL})$ daily for men, individual ideals may vary based on age, gender, genetics, body type, and drug/supplement use. The pattern of wine consumption is also important. Moderate regular drinking gives many health benefits that are lost when drinking is only periodic and heavy, even though the weekly average amount may be the same.

The healthful effects of wine may be enhanced by a healthy diet. The excellent health associated with the Mediterranean diet, which combines moderate wine consumption with a diet rich in fruits, vegetables and whole grains, suggests that wine polyphenols have synergistic effects with compounds found in other types of food (Caimi et al. 2003b). Adding wine to the diet of already healthy individuals may add additional benefits. In nonsmoking, physically active adults of a normal weight that ate a healthy diet, moderate alcohol intake was associated with a lower risk for myocardial infarction and type 2 diabetes than those who abstained (Mukamal et al. 2006, Joosten et al. 2010). However, most medical professionals as well as the American Heart Association agree that heavy drinkers or alcohol abstainers should not be encouraged to drink wine for health reasons. Wine consumption should not replace a healthy lifestyle and necessary pharmacotherapy. Yet, light-to-moderate wine drinkers, without medical complications, may be assured that their wine consumption is a healthy habit.

Lastly, it is obvious that wines could be designed so that, in principal, health benefits could be enhanced. Grapevines exposed to certain environmental conditions, including vineyard elevation and fungal infection produce greater levels of stilbenes (Bavaresco 2003). It is also possible to trigger stilbene production using ultraviolet rays or heavy metals. Vinification procedures that have the most effect on wine phenolics include pomace contact, aging, and grape skin and seed maceration. Nonetheless, these approaches may not appeal to the consumer, since many factors are related to the use of wine beyond the potential of enhancing health benefits.

\section{Literature Cited}

Abu-Amsha Caccetta, R., V. Burke, T.A. Mori, L.J. Beilin, I.B. Puddey, and K.D. Croft. 2001. Red wine polyphenols, in the absence of alcohol, reduce lipid peroxidative stress in smoking subjects. Free Radic. Biol. Med. 30:636-642.

Afaq, F., V.M. Adhami, and N. Ahmad. 2003. Prevention of short-term ultraviolet B radiation-mediated damages by resveratrol in SKH-1 hairless mice. Toxicol. Appl. Pharmacol. 186:28-37.

Agewall, S., S. Wright, R.N. Doughty, G.A. Whalley, M. Duxbury, and N. Sharpe. 2000. Does a glass of red wine improve endothelial function? Eur. Heart J. 21:74-78.
Aggarwal, B.B., and S. Shishodia. 2006. Resveratrol in health and disease. Marcel Dekker, New York.

Aggarwal, B.B., A. Bhardwaj, R.S. Aggarwal, N.P. Seeram, S. Shishodia, and Y. Takada. 2004. Role of resveratrol in prevention and therapy of cancer: Preclinical and clinical studies. Anticancer Res. 24:2783-2840.

Altieri, A., C. Bosetti, S. Gallus, S. Franceschi, L. Dal Maso, R. Talamini, F. Levi, E. Negri, T. Rodriguez, and C. La Vecchia. 2004. Wine, beer and spirits and risk of oral and pharyngeal cancer: A casecontrol study from Italy and Switzerland. Oral Oncol. 40:904-909.

Arendt, B.M., S. Ellinger, K. Kekic, L. Geus, R. Fimmers, U. Spengler, W.U. Muller, and R. Goerlich. 2005. Single and repeated moderate consumption of native or dealcoholized red wine show different effects on antioxidant parameters in blood and DNA strand breaks in peripheral leukocytes in healthy volunteers: A randomized controlled trial (ISRCTN68505294). Nutr. J. 4:33.

Armentia, A. 2008. Adverse reactions to wine: Think outside the bottle. Curr. Opin. Allergy Clin. Immunol. 8:266-269.

Avellone, G., V. Di Garbo, D. Campisi, R. De Simone, G. Raneli, R. Scaglione, and G. Licata. 2006. Effects of moderate Sicilian red wine consumption on inflammatory biomarkers of atherosclerosis. Eur. J. Clin. Nutr. 60:41-47.

Aviram, M., and B. Fuhrman. 2002. Wine flavonoids protect against LDL oxidation and atherosclerosis. Ann. N.Y. Acad. Sci. 957:146-161.

Bagchi, D., M. Bagchi, S. Stohs, S.D. Ray, C.K. Sen, and H.G. Preuss. 2002. Cellular protection with proanthocyanidins derived from grape seeds. Ann. N.Y. Acad. Sci. 957:260-270.

Bailey, D.G., G.K. Dresser, and J.R. Bend. 2003. Bergamottin, lime juice, and red wine as inhibitors of cytochrome P450 3A4 activity: Comparison with grapefruit juice. Clin. Pharmacol. Ther. 73:529-537.

Balestrieri, M.L., et al. 2008. Effect of red wine antioxidants and minor polyphenolic constituents on endothelial progenitor cells after physical training in mice. Int. J. Cardiol. 126:295-297.

Banini, A.E., L.C. Boyd, J.C. Allen, H.G. Allen, and D.L. Sauls. 2006. Muscadine grape products intake, diet and blood constituents of non-diabetic and type 2 diabetic subjects. Nutrition 22:1137-1145.

Bartowsky, E.J., and P.A. Henschke. 2008. Acetic acid bacteria spoilage of bottled red wine-A review. Int. J. Food Microbiol. 125:60-70.

Battilani, P., N. Magan, and A. Logrieco. 2006. European research on ochratoxin A in grapes and wine. Int. J. Food Microbiol. 111 (suppl 1):S2-4.

Bavaresco, L. 2003. Role of viticultural factors on stilbene concentrations of grapes and wine. Drugs Exp. Clin. Res. 29:181-187.

Bertelli, A.A. 2007. Wine, research and cardiovascular disease: Instructions for use. Atherosclerosis 195:242-247.

Bianchini, F., and H. Vainio. 2003. Wine and resveratrol: Mechanisms of cancer prevention? Eur. J. Cancer Prev. 12:417-425.

Blackhurst, D.M., and A.D. Marais. 2006. Concomitant consumption of red wine and polyunsaturated fatty acids in edible oil does not influence the peroxidation status of chylomicron lipids despite increasing plasma catechin concentration. Nutr. Metab. Cardiovasc. Dis. 16:550-558.

Blanco-Colio, L.M., M. Valderrama, L.A. Alvarez-Sala, C. Bustos, M. Ortego, M.A. Hernández-Presa, P. Cancelas, J. Gómez-Gerique, J. Millan, and J. Egido. 2000. Red wine intake prevents nuclear factor-KB activation in peripheral blood mononuclear cells of healthy volunteers during postprandial lipemia. Circulation 102:1020-1026.

Boban, M., D. Modun, I. Music, J. Vukovic, I. Brizic, I. Salamunic, A. Obad, I. Palada, and Z. Dujic. 2006. Red wine induced modulation of vascular function: Separating the role of polyphenols, ethanol, and urates. J Cardiovasc. Pharmacol. 47:695-701. 
Booyse, F.M., W. Pan, H.E. Grenett, D.A. Parks, V.M. Darley-Usmar, K.M. Bradley, and E.M. Tabengwa. 2007. Mechanism by which alcohol and wine polyphenols affect coronary heart disease risk. Ann. Epidemiol. 17:S24-31.

Boveris, A., L. Valdez, and S. Alvarez. 2002. Inhibition by wine polyphenols of peroxynitrite-initiated chemiluminescence and NADH oxidation. Ann. N.Y. Acad. Sci. 957:90-102.

Brereton, P.A., P. Robb, C.M. Sargent, H.M. Crews, and R. Wood. 1997. Determination of lead in wine by graphite furnace atomic absorption spectrophotometry: Interlaboratory study. J. AOAC Int. 80:1287-1297.

Bub, A., B. Watzl, D. Heeb, G. Rechkemmer, and K. Briviba. 2001. Malvidin-3-glucoside bioavailability in humans after ingestion of red wine, dealcoholized red wine and red grape juice. Eur. J. Nutr. 40:113-120.

Cabras, P., and A. Angioni. 2000. Pesticide residues in grapes, wine, and their processing products. J. Agric. Food Chem. 48:967-973.

Caccetta, R.A., K.D. Croft, L.J. Beilin, and I.B. Puddey. 2000. Ingestion of red wine significantly increases plasma phenolic acid concentrations but does not acutely affect ex vivo lipoprotein oxidizability. Am. J. Clin. Nutr. 71:67-74.

Caimi, G., C. Carollo, and R. Lo Presti. 2003a. Diabetes mellitus: Oxidative stress and wine. Curr. Med. Res. Opin. 19:581-586.

Caimi, G., C. Carollo, and R. Lo Presti. 2003b. Wine and endothelial function. Drugs Exp. Clin. Res. 29:235-242.

Caimi, G., C. Carollo, and R. Lo Presti. 2004. Chronic renal failure: Oxidative stress, endothelial dysfunction and wine. Clin. Nephrol. 62:331-335

Carollo, C., R. Presti, and G. Caimi. 2007. Wine, diet, and arterial hypertension. Angiology 58:92-96.

Castilla, P., A. Davalos, J.L. Teruel, F. Cerrato, M. Fernandez-Lucas, J.L. Merino, C.C. Sanchez-Martin, J. Ortuno, and M.A. Lasuncion. 2008. Comparative effects of dietary supplementation with red grape juice and vitamin $\mathrm{E}$ on production of superoxide by circulating neutrophil NADPH oxidase in hemodialysis patients. Am. J. Clin. Nutr. 87:1053-1061.

Castilla, P., R. Echarri, A. Davalos, F. Cerrato, H. Ortega, J.L. Teruel, M.F. Lucas, D. Gomez-Coronado, J. Ortuno, and M.A. Lasuncion. 2006. Concentrated red grape juice exerts antioxidant, hypolipidemic, and antiinflammatory effects in both hemodialysis patients and healthy subjects. Am. J. Clin. Nutr. 84:252-262.

Cesnik, H.B., A. Gregorcic, and F. Cus. 2008. Pesticide residues in grapes from vineyards included in integrated pest management in Slovenia. Food Addit. Contam. Part A Chem. Anal. Control Expo. Risk Assess. 25:438-443.

Chao, C. 2007. Associations between beer, wine, and liquor consumption and lung cancer risk: A meta-analysis. Cancer Epidemiol. Biomarkers Prev. 16:2436-2447.

Chopra, M., P.E. Fitzsimons, J.J. Strain, D.I. Thurnham, and A.N. Howard. 2000. Nonalcoholic red wine extract and quercetin inhibit LDL oxidation without affecting plasma antioxidant vitamin and carotenoid concentrations. Clin. Chem. 46:1162-1170.

Chulze, S.N., C.E. Magnoli, and A.M. Dalcero. 2006. Occurrence of ochratoxin A in wine and ochratoxigenic mycoflora in grapes and dried vine fruits in South America. Int. J. Food Microbiol. 111 (suppl 1):S5-9.

Cleophas, T.J. 1999. Wine, beer and spirits and the risk of myocardial infarction: A systematic review. Biomed. Pharmacother. 53:417-423.

Coimbra, S.R., S.H. Lage, L. Brandizzi, V. Yoshida, and P.L. da Luz. 2005. The action of red wine and purple grape juice on vascular reactivity is independent of plasma lipids in hypercholesterolemic patients. Braz. J. Med. Biol. Res. 38:1339-1347.
Cordain, L., C.L. Melby, A.E. Hamamoto, D.S. O`Neill, M.A. Cornier, H.A. Barakat, R.G. Israel, and J.O. Hill. 2000. Influence of moderate chronic wine consumption on insulin sensitivity and other correlates of syndrome X in moderately obese women. Metabolism 49:1473-1478.

Corder, R., W. Mullen, N.Q. Khan, S.C. Marks, E.G. Wood, M.J. Carrier, and A. Crozier. 2006. Oenology: Red wine procyanidins and vascular health. Nature 444:566.

Cordova, A.C., L.S. Jackson, D.W. Berke-Schlessel, and B.E. Sumpio. 2005. The cardiovascular protective effect of red wine. J. Am. Coll. Surg. 200:428-439.

Covas, M.I., V. Konstantinidou, E. Mysytaki, M. Fito, T. Weinbrenner, R. De La Torre, M. Farre-Albadalejo, and R. Lamuela-Raventos. 2003. Postprandial effects of wine consumption on lipids and oxidative stress biomarkers. Drugs Exp. Clin. Res. 29:217-223.

Cuevas, A.M., V. Guasch, O. Castillo, V. Irribarra, C. Mizon, A. San Martin, P. Strobel, D. Perez, A.M. Germain, and F. Leighton. 2000. A high-fat diet induces and red wine counteracts endothelial dysfunction in human volunteers. Lipids 35:143-148.

Culpitt, S.V., D.F. Rogers, P.S. Fenwick, P. Shah, C. De Matos, R.E. Russell, P.J. Barnes, and L.E. Donnelly. 2003. Inhibition by red wine extract, resveratrol, of cytokine release by alveolar macrophages in COPD. Thorax 58:942-946.

Daglia, M., A. Papetti, P. Grisoli, C. Aceti, C., Dacarro, and G. Gazzani. 2007. Antibacterial activity of red and white wine against oral streptococci. J. Agric. Food Chem. 55:5038-5042.

Dahl, R., J.M. Henriksen, and H. Harving. 1986. Red wine asthma: A controlled challenge study. J. Allergy Clin. Immunol. 78:1126-1129.

Daroch, F., M. Hoeneisen, C.L. Gonzalez, F. Kawaguchi, F. Salgado, H. Solar, and A. Garcia. 2001. In vitro antibacterial activity of Chilean red wines against Helicobacter pylori. Microbios 104:79-85.

Das, D.K., M. Sato, P.S. Ray, G. Maulik, R.M. Engelman, A.A. Bertelli, and A. Bertelli. 1999. Cardioprotection of red wine: Role of polyphenolic antioxidants. Drugs Exp. Clin. Res. 25:115-120.

Davalos, A., C. Fernandez-Hernando, F. Cerrato, J. Martinez-Botas, D. Gomez-Coronado, C. Gomez-Cordoves, and M.A. Lasuncion 2006. Red grape juice polyphenols alter cholesterol homeostasis and increase LDL-receptor activity in human cells in vitro. J. Nutr. 136:1766-1773.

de Gaetano, G., A. De Curtis, A. di Castelnuovo, M.B. Donati, L. Iacoviello, and S. Rotondo. 2002. Antithrombotic effect of polyphenols in experimental models: A mechanism of reduced vascular risk by moderate wine consumption. Ann. N.Y. Acad. Sci. 957:174-188.

de Gaetano, G., A. Di Castelnuovo, M.B. Donati, and L. Iacoviello. 2003. The Mediterranean lecture: Wine and thrombosis-From epidemiology to physiology and back. Pathophysiol. Haemost. Thromb. 33:466-471.

de la Torre, R., M.I. Covas, M.A. Pujadas, M. Fito, and M. Farre. 2006. Is dopamine behind the health benefits of red wine? Eur. J. Nutr. 45:307-310.

de Lange, D. W., W.L. Scholman, R.J. Kraaijenhagen, J.W. Akkerman, and A. van de Wiel. 2004. Alcohol and polyphenolic grape extract inhibit platelet adhesion in flowing blood. Eur. J. Clin. Invest. 34:818-824.

de Lorgeril, M., P. Salen, J.L. Martin, F. Boucher, and J. de Leiris. 2008. Interactions of wine drinking with omega-3 fatty acids in patients with coronary heart disease: A fish-like effect of moderate wine drinking. Am. Heart J. 155:175-181.

de Rijke, Y.B., P.N. Demacker, N.A. Assen, L.M. Sloots, M.B. Katan, and A.F. Stalenhoef. 1996. Red wine consumption does not affect oxidizability of low-density lipoproteins in volunteers. Am. J. Clin. Nutr. 63:329-334. 
de Vries, J.H., P.C. Hollman, I. van Amersfoort, M.R. Olthof, and M.B. Katan. 2001. Red wine is a poor source of bioavailable flavonols in men. J. Nutr. 131:745-748.

Dell'Agli, M., A. Busciala, and E. Bosisio. 2004. Vascular effects of wine polyphenols. Cardiovasc. Res. 63:593-602.

Di Castelnuovo, A., S. Rotondo, L. Iacoviello, M.B. Donati, and G. De Gaetano. 2002. Meta-analysis of wine and beer consumption in relation to vascular risk. Circulation 105:2836-2844.

Djousse, L., R.C. Ellison, C.E. McLennan, L.A. Cupples, I. Lipinska, G.H. Tofler, N. Gokce, and J.A. Vita. 1999. Acute effects of a high-fat meal with and without red wine on endothelial function in healthy subjects. Am. J. Cardiol. 84:660-664.

Djurovic, S., K.E. Berge, B. Birkenes, O. Braaten, and L. Retterstø1. 2007. The effect of red wine on plasma leptin levels and vasoactive factors from adipose tissue: A randomized crossover trial. Alcohol Alcoholism 42:525-528.

Dohadwala, M.M., and J.A. Vita. 2009. Grapes and cardiovascular disease. J. Nutr. 139:1788S-1793S.

Donovan, J.L., J.R. Bell, S. Kasim-Karakas, J.B. German, R.L. Walzem, R.J. Hansen, and A.L. Waterhouse. 1999. Catechin is present as metabolites in human plasma after consumption of red wine. J. Nutr. 129:1662-1668.

Dumitrescu, R.G., and P.G. Shields. 2005. The etiology of alcoholinduced breast cancer. Alcohol 35:213-225.

Durak, I., M.Y. Cimen, S. Buyukkocak, M. Kacmaz, and H.S. Ozturk. 1999. The effect of red wine on blood antioxidant potential. Curr. Med. Res. Opin. 15:208-213.

Durak, I., L. Karaca, M.B. Cimen, M. Kacmaz, A. Avci, G. Gubat, and H.S. Ozturk. 2002. Dried white grapes enhance blood antioxidant potential. Nutr. Metab. Cardiovasc. Dis. 12:204-205.

Duthie, G.G., M.W. Pedersen, P.T. Gardner, P.C. Morrice, A.M. Jenkinson, D.B. McPhail, and G.M. Steele. 1998. The effect of whisky and wine consumption on total phenol content and antioxidant capacity of plasma from healthy volunteers. Eur. J. Clin. Nutr. 52:733-736.

Ellinger, S., B.M. Arendt, R. Fimmers, P. Stehle, U. Spengler, and R. Goerlich. 2008. Bolus ingestion but not regular consumption of native or dealcoholized red wine modulates selected immunological functions of leukocytes in healthy volunteers. Ann. Nutr. Metab. 52:288-295.

Espeland, M.A., L. Gu, K.H. Masaki, R.D. Langer, L.H. Coker, M.L. Stefanick, J. Ockene, and S.R. Rapp. 2005. Association between reported alcohol intake and cognition: Results from the Women's Health Initiative Memory Study. Am. J. Epidemiol. 161:228-238.

Estruch, R., E. Sacanella, E. Badia, E. Antunez, J.M. Nicolas, J. Fernandez-Sola, D. Rotilio, G. de Gaetano, E. Rubin, and A. UrbanoMarquez. 2004. Different effects of red wine and gin consumption on inflammatory biomarkers of atherosclerosis: A prospective randomized crossover trial. Effects of wine on inflammatory markers. Atherosclerosis 175:117-123.

Feher, J., G. Lengyel, and A. Lugasi. 2005. Cultural history of wine, the theoretical background of wine therapy. Orv. Hetil. 146:2635-2639.

Fernandez-Pachon, M.S., D. Villano, A.M. Troncoso, and M.C. GarciaParrilla. 2006. Review of the different methods for the evaluation of the in vitro antioxidant activity of wine and study of in vivo effects. Arch. Latinoam. Nutr. 56:110-122

Flamini, R., and A. Panighel. 2006. Mass spectrometry in grape and wine chemistry. Part II: The consumer protection. Mass Spectrom. Rev. 25:741-774.

Flechtner-Mors, M., H.K. Biesalski, C.P. Jenkinson, G. Adler, and H.H. Ditschuneit. 2004. Effects of moderate consumption of white wine on weight loss in overweight and obese subjects. Int. J. Obes. Relat. Metab. Disord. 28:1420-1426.
Folts, J. 1998. Antithrombotic potential of grape juice and red wine for preventing heart attacks. Pharm. Biol. 36:21-27.

Foppa, M., F.D. Fuchs, L. Preissler, A. Andrighetto, G.A. Rosito, and B.B. Duncan. 2002. Red wine with the noon meal lowers post-meal blood pressure: A randomized trial in centrally obese, hypertensive patients. J. Stud. Alcohol 63:247-251.

Frank, T., M. Netzel, G. Strass, R. Bitsch, and I. Bitsch. 2003. Bioavailability of anthocyanidin-3-glucosides following consumption of red wine and red grape juice. Can. J. Physiol. Pharmacol. 81:423-435.

Fuhrman, B., A. Lavy, and M. Aviram. 1995. Consumption of red wine with meals reduces the susceptibility of human plasma and low-density lipoprotein to lipid peroxidation. Am. J. Clin. Nutr. 61:549-554.

Ganguli, M., J. Vander Bilt, J.A. Saxton, C. Shen, and H.H. Dodge. 2005. Alcohol consumption and cognitive function in late life: A longitudinal community study. Neurology 65:1210-1217.

Ganry, O., C. Baudoin, and P. Fardellone. 2000. Effect of alcohol intake on bone mineral density in elderly women: The EPIDOS Study. Epidemiologie de 1'Osteoporose. Am. J. Epidemiol. 151:773-780.

Gao, L., M.N. Weck, C. Stegmaier, D. Rothenbacher, and H. Brenner. 2010. Alcohol consumption, serum gamma-glutamyltransferase, and helicobacter pylori infection in a population-based study among 9733 older adults. Ann. Epidemiol. 20:122-128.

German, J.B., and R.L. Walzem. 2000. The health benefits of wine. Ann. Rev. Nutr. 20:561-593

Goldberg, D.M., V. Garovic-Kocic, E.P. Diamandis, and C.R. PaceAsciak. 1996. Wine: Does the colour count? Clin. Chim. Acta 246:183-193.

Gorelik, S., M. Ligumsky, R. Kohen, and J. Kanner. 2008. A novel function of red wine polyphenols in humans: Prevention of absorption of cytotoxic lipid peroxidation products. FASEB J. 22:41-46.

Gottrand, F., L. Beghin, N. Duhal, B. Lacroix, J.P. Bonte, J.C. Fruchart, and G. Luc. 1999. Moderate red wine consumption in healthy volunteers reduced plasma clearance of apolipoprotein AII. Eur. J. Clin. Invest. 29:387-394.

Grande, L., C. Manterola, E. Ros, G. Lacima, and C. Pera. 1997. Effects of red wine on 24-hour esophageal $\mathrm{pH}$ and pressures in healthy volunteers. Dig. Dis. Sci. 42:1189-1193.

Greenblatt, D.J., L.L. von Moltke, E.S. Perloff, Y. Luo, J.S. Harmatz, and M.A. Zinny. 2006. Interaction of flurbiprofen with cranberry juice, grape juice, tea, and fluconazole: In vitro and clinical studies Clin. Pharmacol. Ther. 79:125-133.

Gresele, P., P. Pignatelli, G. Guglielmini, R. Carnevale, A.M. Mezzasoma, A. Ghiselli, S. Momi, and F. Violi. 2008. Resveratrol, at concentrations attainable with moderate wine consumption, stimulates human platelet nitric oxide production. J. Nutr. 138:1602-1608.

Guarda, E., I. Godoy, R. Foncea, D.D. Perez, C. Romero, R. Venegas, and F. Leighton. 2005. Red wine reduces oxidative stress in patients with acute coronary syndrome. Int. J. Cardiol. 104:35-38.

Guerrero, R.F., M.C. Garcia-Parrilla, B. Puertas, and E. Cantos-Villar 2009. Wine, resveratrol and health: A review. Nat. Prod. Commun. 4:635-658

Hague, T., A. Petroczi, P.L. Andrews, J. Barker, and D.P. Naughton. 2008. Determination of metal ion content of beverages and estimation of target hazard quotients: A comparative study. Chem. Central J. 2:13. doi: 10.1186/1752-153X-1-13.

Halpern, G.M. 2008. A celebration of wine: Wine IS medicine. Inflammopharmacology 16:240-244.

Han, X., T. Zheng, F.M. Foss, S. Ma, T.R. Holford, P. Boyle, B. Leaderer, P. Zhao, M. Dai, and Y. Zhang. 2010. Alcohol consumption and non-Hodgkin lymphoma survival. J. Cancer Surviv. 4:101-109.

Hansen, A.S., P. Marckmann, L.O. Dragsted, I.L. Finne Nielsen, S.E. Nielsen, and M. Gronbaek. 2005. Effect of red wine and red grape 
extract on blood lipids, haemostatic factors, and other risk factors for cardiovascular disease. Eur. J. Clin. Nutr. 59:449-455.

Hijmering, M.L., D.W. de Lange, A. Lorsheyd, R.J. Kraaijenhagen, and A. van de Wiel. 2007. Binge drinking causes endothelial dysfunction, which is not prevented by wine polyphenols: A small trial in healthy volunteers. Neth. J. Med. 65:29-35.

Hocking, A.D., S.L. Leong, B.A. Kazi, R.W. Emmett, and E.S. Scott. 2007. Fungi and mycotoxins in vineyards and grape products. Int. J. Food Microbiol. 119:84-88.

Howard, A.A., J.H. Arnsten, and M.N. Gourevitch. 2004. Effect of alcohol consumption on diabetes mellitus: A systematic review, Ann. Int. Med. 140:211-219.

Imhof, A., R. Blagieva, N. Marx, and W. Koenig. 2008. Drinking modulates monocyte migration in healthy subjects: A randomised intervention study of water, ethanol, red wine and beer with or without alcohol. Diab. Vasc. Dis. Res. 5:48-53.

Imhof, A., I. Plamper, S. Maier, G. Trischler, and W. Koenig. 2009. Effect of drinking on adiponectin in healthy men and women: A randomized intervention study of water, ethanol, red wine, and beer with or without alcohol. Diabet. Care 32:1101-1103.

Imhof, A., M. Woodward, A. Doering, N. Helbecque, H. Loewel, P. Amouyel, G.D. Lowe, and W. Koenig. 2004. Overall alcohol intake, beer, wine, and systemic markers of inflammation in western Europe: Results from three MONICA samples (Augsburg, Glasgow, Lille). Eur. Heart J. 25:2092-2100.

Iriti, M., and F. Faoro. 2009. Bioactivity of grape chemicals for human health. Nat. Prod. Commun. 4:611-634.

Jang, M., L. Cai, G.O. Udeani, K.V. Slowing, C.F. Thomas, C.W. Beecher, H.H. Fong, N.R. Farnsworth, A.D. Kinghorn, R.G. Mehta, R.C. Moon, and J.M. Pezzuto. 1997. Cancer chemopreventive activity of resveratrol, a natural product derived from grapes. Science 275:218-220.

Jarisch, R., and F. Wantke. 1996. Wine and headache. Int. Arch. Allergy Immunol. 110:7-12.

Jimenez, J.P., J. Serrano, M. Tabernero, S. Arranz, M.E. Diaz-Rubio, L. Garcia-Diz, I. Goni, and F. Saura-Calixto. 2008. Effects of grape antioxidant dietary fiber in cardiovascular disease risk factors. Nutrition 24:646-653.

Johansen, K.M., S. Skorpe, J.O. Olsen, and B. Osterud. 1999. The effect of red wine on the fibrinolytic system and the cellular activation reactions before and after exercise. Thromb. Res. 96:355-363.

Joosten, M.M., J.W. Beulens, S. Kersten, and H.F. Hendriks. 2008. Moderate alcohol consumption increases insulin sensitivity and ADIPOQ expression in postmenopausal women: A randomised, crossover trial. Diabetologia 51:1375-1381.

Joosten, M.M., D.E. Grobbee, A.D. van der, W.M. Verschuren, H.F. Hendriks, and J.W. Beulens. 2010. Combined effect of alcohol consumption and lifestyle behaviors on risk of type 2 diabetes. Am. J. Clin. Nutr. 91:1777-1783.

Joseph, J.A., B. Shukitt-Hale, and L.M. Willis. 2009. Grape juice, berries, and walnuts affect brain aging and behavior. J. Nutr. 139:1813S-1817S.

Kamholz, S.L. 2006. Wine, spirits and the lung: Good, bad or indifferent? Trans. Am. Clin. Climatol. Assoc. 117:129-145.

Kar, P., D. Laight, H.K. Rooprai, K.M. Shaw, and M. Cummings. 2009. Effects of grape seed extract in Type 2 diabetic subjects at high cardiovascular risk: A double blind randomized placebo controlled trial examining metabolic markers, vascular tone, inflammation, oxidative stress and insulin sensitivity. Diabet. Med. 26:526-531.

Karatzi, K., C. Papamichael, E. Karatzis, T.G. Papaioannou, P.T. Voidonikola, G.D. Vamvakou, J. Lekakis, and A. Zampelas. 2008. Postprandial improvement of endothelial function by red wine and olive oil antioxidants: A synergistic effect of components of the Mediterranean diet. J. Am. Coll. Nutr. 27:448-453.

Karatzi, K.N., C.M. Papamichael, E.N. Karatzis, T.G. Papaioannou, K.A. Aznaouridis, P.P. Katsichti, K.S. Stamatelopoulos, A. Zampelas, J.P. Lekakis, and M.E. Mavrikakis. 2005. Red wine acutely induces favorable effects on wave reflections and central pressures in coronary artery disease patients. Am. J. Hypertens. 18:1161-1167.

Karlson, B., B. Leijd, and K. Hellstrom. 1986. On the influence of vitamin K-rich vegetables and wine on the effectiveness of warfarin treatment. Acta Med. Scand. 220:347-350.

Katiyar, S.K. 2008. Grape seed proanthocyanidines and skin cancer prevention: Inhibition of oxidative stress and protection of immune system. Mol. Nutr. Food Res. 52 (suppl 1):S71-76.

Kaur, M., C. Agarwal, and R. Agarwal. 2009. Anticancer and cancer chemopreventive potential of grape seed extract and other grapebased products. J. Nutr. 139:1806S-1812S.

Keevil, J.G., H.E. Osman, J.D. Reed, and J.D., Folts. 2000. Grape juice, but not orange juice or grapefruit juice, inhibits human platelet aggregation. J. Nutr. 130:53-56.

Kikura, M., J.H. Levy, R.A. Safon, M.K. Lee, and F. Szlam. 2004. The influence of red wine or white wine intake on platelet function and viscoelastic property of blood in volunteers. Platelets 15:37-41.

Kiviniemi, T.O., A. Saraste, J.O. Toikka, M. Saraste, O.T. Raitakari, J.P. Parkka, T. Lehtimaki, J.J. Hartiala, J. Viikari, and J.W. Koskenvuo. 2007. A moderate dose of red wine, but not de-alcoholized red wine increases coronary flow reserve. Atherosclerosis 195:e176-181.

Ko, S.H., S.W. Choi, S.K. Ye, B.L. Cho, H.S. Kim, and M.H. Chung. 2005. Comparison of the antioxidant activities of nine different fruits in human plasma. J. Med. Food. 8:41-46.

Koppes, L.L., J.M. Dekker, H.F. Hendriks, L.M. Bouter, and R.J. Heine. 2005. Moderate alcohol consumption lowers the risk of type 2 diabetes: A meta-analysis of prospective observational studies. Diabet. Care 28:719-725.

Kubo, A., T.R. Levin, G. Block, G.J. Rumore, C.P. Quesenberry, Jr., P. Buffler, and D.A. Corley. 2009. Alcohol types and sociodemographic characteristics as risk factors for Barrett's esophagus. Gastroenterology 136:806-815.

Lagrue-Lak-Hal, A.H., and R. Andriantsitohaina. 2006. Red wine and cardiovascular risks. Arch. Mal. Coeur Vaiss. 99:1230-1235.

Lavy, A., B. Fuhrman, A. Markel, G. Dankner, A. Ben-Amotz, D. Presser, and M. Aviram. 1994. Effect of dietary supplementation of red or white wine on human blood chemistry, hematology and coagulation: Favorable effect of red wine on plasma high-density lipoprotein. Ann. Nutr. Metab. 38:287-294.

Leifert, W.R., and M.Y. Abeywardena. 2008. Cardioprotective actions of grape polyphenols. Nutr. Res. 28:729-737.

Leighton, F., et al. 1999. Plasma polyphenols and antioxidants, oxidative DNA damage and endothelial function in a diet and wine intervention study in humans. Drugs Exp. Clin. Res. 25:133-141.

Leighton, F., S. Miranda-Rottmann, and I. Urquiaga. 2006. A central role of eNOS in the protective effect of wine against metabolic syndrome. Cell Biochem. Funct. 24:291-298.

Letenneur, L. 2004. Risk of dementia and alcohol and wine consumption: A review of recent results. Biol. Res. 37:189-193.

Levanon, D., B. Goss, and J.D. Chen. 2002. Inhibitory effect of white wine on gastric myoelectrical activity and the role of vagal tone. Dig. Dis. Sci. 47:2500-2505.

Li, H., X.H. Liang, A.Q. Guo, and D.C. Huang. 2006. Arginine metabolism in wine malolactic bacteria. Acta Microbiol. Sinica 46:663-667.

Lindberg, M.L., and E.A. Amsterdam. 2008. Alcohol, wine, and cardiovascular health. Clin. Cardiol. 31:347-351. 
Littlewood, J.T., C. Gibb, V. Glover, M. Sandler, P.T. Davies, and F.C Rose. 1988. Red wine as a cause of migraine. Lancet 1:558-559.

Liu, J. Y., and J.Y. Zhong. 2008. Study on protective effect of grape procyanidins in radiation injury in radiation-contacted persons. Chi. J. Prev. Med. 42:264-267.

Liu, L., Y. Wang, K.S. Lam, and A. Xu. 2008. Moderate wine consumption in the prevention of metabolic syndrome and its related medical complications. Endocr. Metab. Immun. Disord. Drug Targets 8:89-98.

Lopez-Velez, M., F. Martinez-Martinez, and C. Del Valle-Ribes. 2003. The study of phenolic compounds as natural antioxidants in wine. Crit. Rev. Food Sci. Nutr. 43:233-244.

Magrone, T., G. Candore, C. Caruso, E. Jirillo, and V. Covelli. 2008. Polyphenols from red wine modulate immune responsiveness: Biological and clinical significance. Curr. Pharm. Des. 14:2733-2748.

Mahady, G.B., S.L. Pendland, and L.R. Chadwick. 2003. Resveratrol and red wine extracts inhibit the growth of CagA+ strains of Helicobacter pylori in vitro. Am. J. Gastroenterol. 98:1440-1441.

Marfella, R., et al. 2006. Effect of moderate red wine intake on cardiac prognosis after recent acute myocardial infarction of subjects with type 2 diabetes mellitus. Diabet. Med. 23:974-981.

Martini, S., C. D’Addario, D. Braconi, G. Bernardini, L. Salvini, C. Bonechi, N. Figura, A. Santucci, and C. Rossi. 2009. Antibacterial activity of grape extracts on cagA-positive and -negative Helicobacter pylori clinical isolates. J. Chemother. 21:507-513.

Mateo, R., A. Medina, E.M. Mateo, F. Mateo, and M. Jimenez. 2007. An overview of ochratoxin A in beer and wine. Int. J. Food Microbiol. 119:79-83.

Mehlig, K., I. Skoog, X. Guo, M. Schutze, D. Gustafson, M., Waern, S. Ostling, C. Bjorkelund, and L. Lissner. 2008. Alcoholic beverages and incidence of dementia: 34-year follow-up of the prospective population study of women in Goteborg. Am. J. Epidemiol. 167: 684-691.

Mezzano, D. 2004. Distinctive effects of red wine and diet on haemostatic cardiovascular risk factors. Biol. Res. 37:217-224.

Micallef, M., L. Lexis, and P. Lewandowski. 2007. Red wine consumption increases antioxidant status and decreases oxidative stress in the circulation of both young and old humans. Nutr. J. 6:27.

Misso, N.L., S. Aggarwal, P.J. Thompson, and H. Vally. 2009. Increases in urinary $9 \alpha, 11 \beta$-prostaglandin $\mathrm{F}_{2}$ indicate mast cell activation in wine-induced asthma. Int. Arch Allergy Immunol. 149:127-132.

Modun, D., I. Music, J. Vukovic, I. Brizic, V. Katalinic, A. Obad, I. Palada, Z. Dujic, and M. Boban. 2008. The increase in human plasma antioxidant capacity after red wine consumption is due to both plasma urate and wine polyphenols. Atherosclerosis 197:250-256.

Mukamal, K.J., S.E. Chiuve, and E.B. Rimm. 2006. Alcohol consumption and risk for coronary heart disease in men with healthy lifestyles. Arch. Int. Med. 166:2145-2150.

Naissides, M., J.C. Mamo, A.P. James, and S. Pal. 2004. The effect of acute red wine polyphenol consumption on postprandial lipaemia in postmenopausal women. Atherosclerosis 177:401-408.

Naissides, M., J.C. Mamo, A.P. James, and S. Pal. 2006a. The effect of chronic consumption of red wine on cardiovascular disease risk factors in postmenopausal women. Atherosclerosis 185:438-445.

Naissides, M., S. Pal, J.C. Mamo, A.P. James, and S. Dhaliwal. 2006b. The effect of chronic consumption of red wine polyphenols on vascular function in postmenopausal women. Eur. J. Clin. Nutr. 60:740-745.

Nakamura, T., N. Fujiwara, T. Sugaya, Y. Ueda, and H. Koide. 2009. Effect of red wine on urinary protein, 8-hydroxydeoxyguanosine, and liver-type fatty acid-binding protein excretion in patients with diabetic nephropathy. Metabolism 58:1185-1190.
Napoli, R., V. Guardasole, V. Angelini, A.M. Capasso, E. Zarra, A. Cittadini, M. Matarazzo, and L. Sacca. 2004. Food and red wine do not exert acute effects on vascular reactivity. Metabolism 53:1081-1086.

Nassiri-Asl, M., and H. Hosseinzadeh. 2009. Review of the pharmacological effects of Vitis vinifera (grape) and its bioactive compounds. Phytother. Res. 23:1197-1204.

Nigdikar, S.V., N.R. Williams, B.A. Griffin, and A.N. Howard. 1998. Consumption of red wine polyphenols reduces the susceptibility of low-density lipoproteins to oxidation in vivo. Am. J. Clin. Nutr. $68: 258-265$

Njajou, O.T., A.M. Kanaya, P. Holvoet, S. Connelly, E.S. Strotmeyer, T.B. Harris, S.R. Cummings, and W.C. Hsueh. 2009. Association between oxidized LDL, obesity and type 2 diabetes in a populationbased cohort, the Health, Aging and Body Composition Study. Diabet. Metab. Res. Rev. 25:733-739.

O’Byrne, D.J., S. Devaraj, S.M. Grundy, and I. Jialal. 2002. Comparison of the antioxidant effects of Concord grape juice flavonoids $\alpha$-tocopherol on markers of oxidative stress in healthy adults. Am. J. Clin. Nutr. 76:1367-1374.

Oak, M.H., J. El Bedoui, and V.B. Schini-Kerth. 2005. Antiangiogenic properties of natural polyphenols from red wine and green tea. J. Nutr. Biochem. 16:1-8

Obisesan, T.O., R. Hirsch, O. Kosoko, L. Carlson, and M. Parrott. 1998. Moderate wine consumption is associated with decreased odds of developing age-related macular degeneration in NHANES-1. J. Am. Geriatr. Soc. 46:1-7.

Opie, L.H., and S. Lecour. 2007. The red wine hypothesis: From concepts to protective signalling molecules. Eur. Heart J. 28:1683-1693.

Pace-Asciak, C.R., O. Rounova, S.E. Hahn, E.P. Diamandis, and D.M. Goldberg. 1996. Wines and grape juices as modulators of platelet aggregation in healthy human subjects. Clin. Chim. Acta 246:163-182.

Papamichael, C.M., K.N. Karatzi, T.G. Papaioannou, E.N. Karatzis, P. Katsichti, V. Sideris, N. Zakopoulos, A. Zampelas, and J.P. Lekakis. 2008. Acute combined effects of olive oil and wine on pressure wave reflections: Another beneficial influence of the Mediterranean diet antioxidants? J. Hypertens. 26:223-229.

Park, Y.K., J.S. Kim, and M.H. Kang. 2004. Concord grape juice supplementation reduces blood pressure in Korean hypertensive men: Double-blind, placebo controlled intervention trial. Biofactors 22:145-147.

Park, Y.K., S.H. Lee, E. Park, J.S. Kim, and M.H. Kang. 2009. Changes in antioxidant status, blood pressure, and lymphocyte DNA damage from grape juice supplementation. Ann. N.Y. Acad. Sci. 1171:385-390

Park, Y.K., E. Park, J.S. Kim, and M.H. Kang. 2003. Daily grape juice consumption reduces oxidative DNA damage and plasma free radical levels in healthy Koreans. Mutat. Res. 529:77-86.

Pasten, C., and H. Grenett. 2006. Wine, fibrinolysis and health. Rev. Med. Chil. 134:1040-1048.

Pehl, C., M. Frommherz, B. Wendl, T. Schmidt, and A. Pfeiffer. 2000. Effect of white wine on esophageal peristalsis and acid clearance Sca. J. Gastroenterol. 35:1255-1259.

Pehl, C., B. Wendl, and A. Pfeiffer. 2006. White wine and beer induce gastro-oesophageal reflux in patients with reflux disease. Aliment Pharmacol. Ther. 23:1581-1586.

Pellegrini, N., F.I. Pareti, F. Stabile, A. Brusamolino, and P. Simonetti. 1996. Effects of moderate consumption of red wine on platelet aggregation and haemostatic variables in healthy volunteers. Eur. J. Clin. Nutr. 50:209-213

Percival, S.S. 2009. Grape consumption supports immunity in animals and humans. J. Nutr. 139:1801S-1805S.

Perez-Jimenez, J., and F. Saura-Calixto. 2008. Grape products and cardiovascular disease risk factors. Nutr. Res. Rev. 21:158-173. 
Peters, R., J. Peters, J. Warner, N. Beckett, and C. Bulpitt. 2008. Alcohol, dementia and cognitive decline in the elderly: A systematic review. Age Ageing 37:505-512.

Pezzuto, J.M. 2008. Grapes and human health: A perspective. J. Agric. Food Chem. 56:6777-6784.

Pezzuto, J.M., V. Venkatasubramanian, M. Hamad, and K.R. Morris. 2009. Unraveling the relationship between grapes and health. J. Nutr. 139:1783S-1787S.

Pignatelli, P., A. Ghiselli, B. Buchetti, R. Carnevale, F. Natella, G. Germano, F. Fimognari, S. Di Santo, L. Lenti, and F. Violi. 2006. Polyphenols synergistically inhibit oxidative stress in subjects given red and white wine. Atherosclerosis 188:77-83.

Pignatelli, P., L. Lenti, F.M. Pulcinelli, R. Catasca, G. Saccani, G. Germano, A. Marcoccia, M.A. Silvestri, A. Ghiselli, and F. Violi. 2002. Red and white wine differently affect collagen-induced platelet aggregation. Pathophysiol. Haemost. Thromb. 32:356-358.

Pinder, R.M., and M. Sandler. 2004. Alcohol, wine and mental health: Focus on dementia and stroke. J. Psychopharmacology 18:449-456.

Pinzani, P., E. Petruzzi, C. Orlando, F. Malentacchi, I. Petruzzi, M. Pazzagli, and G. Masotti. 2005. Healthy centenarian subjects: The effect of red wine consumption on liver function tests. J. Endocrinol. Invest. 28:120-122.

Presti, R.L., C. Carollo, and G. Caimi. 2007. Wine consumption and renal diseases: New perspectives. Nutrition 23:598-602.

Preuss, H.G., D. Wallerstedt, N. Talpur, S.O. Tutuncuoglu, B. Echard, A. Myers, M. Bui, and D. Bagchi. 2000. Effects of niacin-bound chromium and grape seed proanthocyanidin extract on the lipid profile of hypercholesterolemic subjects: A pilot study. J. Med. 31:227-246.

Puja, A., F. Halaweish, and C. Dwivedi. 2007. Antioxidant effects and drug interactions of resveratrol present in wine. J. Wine Res. 18:59-71.

Rajdl, D., J. Racek, L. Trefil, and K. Siala. 2007. Effect of white wine consumption on oxidative stress markers and homocysteine levels. Physiol. Res. 56:203-212.

Rakotovao, A., C. Berthonneche, A. Guiraud, M. de Lorgeril, P. Salen, J. de Leiris, and F. Boucher. 2004. Ethanol, wine, and experimental cardioprotection in ischemia/reperfusion: Role of the prooxidant/ antioxidant balance. Antioxid. Redox. Signal. 6:431-438.

Renaud, S., and R. Gueguen. 1998. The French paradox and wine drinking. Novartis Found. Symp. 216:208-217; discussion 217-222:152-208.

Retterstol, L., K.E. Berge, O. Braaten, L. Eikvar, T.R. Pedersen, and L. Sandvik. 2005. A daily glass of red wine: Does it affect markers of inflammation? Alcohol Alcoholism 40:102-105.

Rimm, E.B., A. Klatsky, D. Grobbee, and M.J. Stampfer. 1996. Review of moderate alcohol consumption and reduced risk of coronary heart disease: Is the effect due to beer, wine, or spirits. BMJ 312:731-736.

Robinson, J. 2006. The Oxford Companion to Wine. Oxford University Press, New York.

Rodrigo, R., and G. Rivera. 2002. Renal damage mediated by oxidative stress: A hypothesis of protective effects of red wine. Free Radic. Biol. Med. 33:409-422.

Ruf, J.C. 2003. Overview of epidemiological studies on wine, health and mortality. Drugs Exp. Clin. Res. 29:173-179.

Ruf, J.C. 2004. Alcohol, wine and platelet function. Biol. Res. 37:209215.

Ruggiero, P., G. Rossi, F. Tombola, L. Pancotto, L. Lauretti, G. Del Giudice, and M. Zoratti. 2007. Red wine and green tea reduce H pylori- or VacA-induced gastritis in a mouse model. World J. Gastroenterol. 13:349-354.

Sacanella, E., M. Vazquez-Agell, M.P. Mena, E. Antunez, J. FernandezSola, J.M. Nicolas, R.M. Lamuela-Raventos, E. Ros, and R. Estruch. 2007. Down-regulation of adhesion molecules and other inflammatory biomarkers after moderate wine consumption in healthy women: A randomized trial. Am. J. Clin. Nutr. 86:1463-1469.

Sandler, M., N.Y. Li, N. Jarrett, and V. Glover. 1995. Dietary migraine: Recent progress in the red (and white) wine story. Cephalalgia 15:101-103.

Sano, A., R. Uchida, M. Saito, N. Shioya, Y. Komori, Y. Tho, and N. Hashizume. 2007. Beneficial effects of grape seed extract on malondialdehyde-modified LDL. J. Nutr. Sci. Vitaminol. 53:174-182.

Saremi, A., and R. Arora. 2008. The cardiovascular implications of alcohol and red wine. Am. J. Ther. 15:265-277.

Schafer, A., and J. Bauersachs. 2002. High-altitude pulmonary edema: Potential protection by red wine. Nutr. Metab. Cardiovasc. Dis. 12:306-310.

Senault, C., D. Betoulle, G. Luc, P. Hauw, D. Rigaud, and F. Fumeron. 2000. Beneficial effects of a moderate consumption of red wine on cellular cholesterol efflux in young men. Nutr. Metab. Cardiovasc. Dis. 10:63-69.

Shai, I., J. Wainstein, I. Harman-Boehm, I. Raz, D. Fraser, A. Rudich, and M.J. Stampfer. 2007. Glycemic effects of moderate alcohol intake among patients with type 2 diabetes: A multicenter, randomized, clinical intervention trial. Diabet. Care. 30:3011-3016.

Sharpe, P.C., L.T. McGrath, E. McClean, I.S. Young, and G.P. Archbold. 1995. Effect of red wine consumption on lipoprotein (a) and other risk factors for atherosclerosis. QJM 88:101-108.

Soleas, G.J., E.P. Diamandis, and D.M. Goldberg. 1997. Wine as a biological fluid: History, production, and role in disease prevention. J. Clin. Lab. Anal. 11:287-313.

Spaak, J., A.C. Merlocco, G.J. Soleas, G. Tomlinson, B.L. Morris, P. Picton, C.F. Notarius, C.T. Chan, and J.S. Floras. 2008. Dose-related effects of red wine and alcohol on hemodynamics, sympathetic nerve activity, and arterial diameter. Am. J. Physiol. Heart Circ. Physiol. 294:H605-612.

Stampfer, M.J., J.H. Kang, J. Chen, R. Cherry, and F. Grodstein. 2005. Effects of moderate alcohol consumption on cognitive function in women. N. Engl. J. Med. 352:245-253.

Stein, J.H., J.G. Keevil, D.A. Wiebe, S. Aeschlimann, and J.D. Folts. 1999. Purple grape juice improves endothelial function and reduces the susceptibility of LDL cholesterol to oxidation in patients with coronary artery disease. Circulation 100:1050-1055.

Szmitko, P.E., and S. Verma. 2005. Antiatherogenic potential of red wine: Clinician update. Am. J. Physiol. Heart Circ. Physiol. 288:H2023-2030.

Takkouche, B., C. Regueira-Mendez, R. Garcia-Closas, A. Figueiras, J.J. Gestal-Otero, and M.A. Hernan. 2002. Intake of wine, beer, and spirits and the risk of clinical common cold. Am. J. Epidemiol. $155: 853-858$

Tredici, G., M. Miloso, G. Nicolini, S. Galbiati, G. Cavaletti, and A. Bertelli. 1999. Resveratrol, map kinases and neuronal cells: Might wine be a neuroprotectant? Drugs Exp. Clin. Res. 25:99-103.

Tsang, C., S. Higgins, G.G. Duthie, S.J. Duthie, M. Howie, W. Mullen, M.E. Lean, and A. Crozier. 2005. The influence of moderate red wine consumption on antioxidant status and indices of oxidative stress associated with CHD in healthy volunteers. Br. J. Nutr. 93:233-240.

Tsunoda, S.M., R.Z. Harris, U. Christians, R.L. Velez, R.B. Freeman, L.Z. Benet, and A. Warshaw. 2001. Red wine decreases cyclosporine bioavailability. Clin. Pharmacol. Ther. 70:462-467.

Ursini, F., and A. Sevanian. 2002. Wine polyphenols and optimal nutrition. Ann. N.Y. Acad. Sci. 957:200-209.

Vally, H., A. Carr, J. El-Saleh, and P. Thompson. 1999. Wine-induced asthma: A placebo-controlled assessment of its pathogenesis. J. Allergy Clin. Immunol. 103:41-46. 
Vally, H., P.J. Thompson, and N.L. Misso. 2007. Changes in bronchial hyperresponsiveness following high- and low-sulphite wine challenges in wine-sensitive asthmatic patients. Clin. Exp. Allergy. 37:1062-1066.

van der Gaag, M.S., R. van den Berg, H. van den Berg, G. Schaafsma, and H.F. Hendriks. 2000. Moderate consumption of beer, red wine and spirits has counteracting effects on plasma antioxidants in middle-aged men. Eur. J. Clin. Nutr. 54:586-591.

van Golde, P.H., L.M. Sloots, W.P. Vermeulen, J.P. Wielders, H.C. Hart, B.N. Bouma, and A. van de Wiel. 1999. The role of alcohol in the anti low density lipoprotein oxidation activity of red wine. Atherosclerosis 147:365-370.

van Golde, P.M., R.J. Kraaijenhagen, B.N. Bouma, and A. van de Wiel. 2003. No acute effect of red wine on the coagulation pathway in healthy men. Alcohol 29:183-186.

Van Tol, A., J.E. Groener, L.M. Scheek, T. Van Gent, J. Veenstra, H. Van de Pol, H.F. Hendriks, and G. Schaafsma. 1995. Induction of net mass lipid transfer reactions in plasma by wine consumption with dinner. Eur. J. Clin. Invest. 25:390-395.

Vandenbroucke, J.P. 1991. Diseases charted in the Nederlandsch Tijdschrift voor Geneeskunde, 1857-1880. Nederlands tijdschrift voor geneeskunde 135:1819-1826.

Vazquez-Agell, M., et al. 2007. Inflammatory markers of atherosclerosis are decreased after moderate consumption of cava (sparkling wine) in men with low cardiovascular risk. J. Nutr. 137:2279-2284.

Vigna, G.B., et al. 2003. Effect of a standardized grape seed extract on low-density lipoprotein susceptibility to oxidation in heavy smokers. Metabolism 52:1250-1257.

Vogels, N., I.M. Nijs, and M.S. Westerterp-Plantenga. 2004. The effect of grape-seed extract on $24 \mathrm{~h}$ energy intake in humans. Eur. J. Clin. Nutr. 58:667-673.

Walzem, R.L. 2008. Wine and health: State of proofs and research needs. Inflammopharmacology 16:265-271.

Wang, Z., Y. Huang, J. Zou, K. Cao, Y. Xu, and J.M. Wu. 2002. Effects of red wine and wine polyphenol resveratrol on platelet aggregation in vivo and in vitro. Int. J. Mol. Med. 9:77-79.

Wantke, F., W. Hemmer, T. Haglmuller, M. Gotz, and R. Jarisch. 1996. Histamine in wine. Bronchoconstriction after a double-blind placebo-controlled red wine provocation test. Int. Arch. Allergy Immunol. 110:397-400.

Ward, N.C., J.M. Hodgson, K.D. Croft, V. Burke, L.J. Beilin, and I.B. Puddey. 2005. The combination of vitamin C and grape-seed polyphenols increases blood pressure: A randomized, double-blind, placebo-controlled trial. J. Hypertens. 23:427-434.

Waterhouse, A.L. 2002. Wine phenolics. Ann. N.Y. Acad. Sci. 957:21-36.

Watzl, B., A. Bub, K. Briviba, and G. Rechkemmer. 2002. Acute intake of moderate amounts of red wine or alcohol has no effect on the immune system of healthy men. Eur. J. Nutr. 41:264-270.

Watzl, B., A. Bub, G. Pretzer, S. Roser, S.W. Barth, and G. Rechkemmer. 2004. Daily moderate amounts of red wine or alcohol have no effect on the immune system of healthy men. Eur. J. Clin. Nutr. 58:40-45.

Whelan, A.P., W.H. Sutherland, M.P. McCormick, D.J. Yeoman, S.A. de Jong, and M.J. Williams. 2004. Effects of white and red wine on endothelial function in subjects with coronary artery disease. Intern. Med. J. 34:224-228

Wu, C.D. 2009. Grape products and oral health. J. Nutr. 139:1818S$1823 \mathrm{~S}$.

Yadav, M., et al. 2009. Biological and medicinal properties of grapes and their bioactive constituents: An update. J. Med. Food. 12:473-484.

Young, J.F., L.O. Dragsted, B. Daneshvar, S.T. Lauridsen, M. Hansen, and B. Sandstrom. 2000. The effect of grape-skin extract on oxidative status. Br. J. Nutr. 84:505-513.

Zern, T.L., R.J. Wood, C. Greene, K.L. West, Y. Liu, D. Aggarwal, N.S. Shachter, and M.L. Fernandez. 2005. Grape polyphenols exert a cardioprotective effect in pre- and postmenopausal women by lowering plasma lipids and reducing oxidative stress. J. Nutr. 135:1911-1917.

Ziegler, S., K. Kostner, C. Thallinger, A. Bur, M. Brunner, M. Wolzt, and C. Joukhadar. 2005. Wine ingestion has no effect on lipid peroxidation products. Pharmacology 75:152-156.

Zilkens, R.R., V. Burke, J.M. Hodgson, A. Barden, L.J. Beilin, and I.B. Puddey. 2005. Red wine and beer elevate blood pressure in normotensive men. Hypertension 45:874-879.

Zunino, S. 2009. Type 2 diabetes and glycemic response to grapes or grape products. J. Nutr. 139:1794S-1800S. 